\title{
Classification of Hydrometeors Based on Polarimetric Radar Measurements: Development of Fuzzy Logic and Neuro-Fuzzy Systems, and In Situ Verification
}

\author{
HongPing LiU AND V. Chandrasekar \\ Colorado State University, Fort Collins, Colorado
}

(Manuscript received 27 October 1998, in final form 27 April 1999)

ABSTRACT

\begin{abstract}
A fuzzy logic and neuro-fuzzy system for classification of hydrometeor type based on polarimetric radar measurements is described in this paper. The hydrometeor classification system is implemented by using fuzzy logic and a neural network, where the fuzzy logic is used to infer hydrometeor type, and the neural network learning algorithm is used for automatic adjustment of the parameters of the fuzzy sets in the fuzzy logic system according to prior knowledge. Five radar measurements, namely, horizontal reflectivity $\left(Z_{H}\right)$, differential reflectivity $\left(Z_{\mathrm{DR}}\right)$, differential propagation phase shift $\left(K_{\mathrm{DP}}\right)$, correlation coefficient $\left[\rho_{H V}(0)\right]$, and linear depolarization ratio $\left(L_{\mathrm{DR}}\right)$, and corresponding altitude, have been used as input variables to the neuro-fuzzy network. The output of the neuro-fuzzy system is one of the many possible hydrometeor types: 1) drizzle, 2) rain, 3) dry and low density snow, 4) dry and high-density crystals, 5) wet and melting snow, 6) dry graupel, 7) wet graupel, 8) small hail, 9) large hail, and 10) a mixture of rain and hail. The neuro-fuzzy classifier is more advantageous than a simple neural network or a fuzzy logic classifier because it is more transparent (instead of a "black box") and can learn the parameter of the system from the past data (unlike a fuzzy logic system). The hydrometeor classifier has been applied to several case studies and the results are compared against in situ observations.
\end{abstract}

\section{Introduction}

Polarimetric radar is a useful remote sensing tool for the study of storm microphysics. The polarimetric radar measurements are sensitive to the types, shapes, and size distributions, as well as fall behaviors of the hydrometeors in the radar resolution volume. As a result, extensive information about the microphysics of the hydrometeors is contained in the multiparameter radar measurements. Retrieving the microphysical information from polarimetric radar observation has been an active topic of research. Eventually, these microphysical inferences can be utilized to initialize the cloud/mesoscale numerical weather prediction models. The goal of this paper is to develop a technique to classify hydrometeor types based on polarimetric radar measurements. Hydrometeor type classification has a wide variety of applications, such as interpretation of polarimetric radar data, study of precipitation formation and life cycle, and choice of the right algorithm for precipitation estimation. Based on the existing polarimetric radar measurements and the current knowledge about these hydro-

Corresponding author address: Dr. V. Chandrasekar, Dept. of Electrical Engineering, Colorado State University, Fort Collins, CO 80523-1373

E-mail: chandra@engr.colostate.edu meteors, a neuro-fuzzy system for automatic classification of hydrometeors is developed in this paper.

\section{a. Hydrometeor type classification}

The process of hydrometeor type classification from remotely sensed radar data cannot be obtained as a sim-

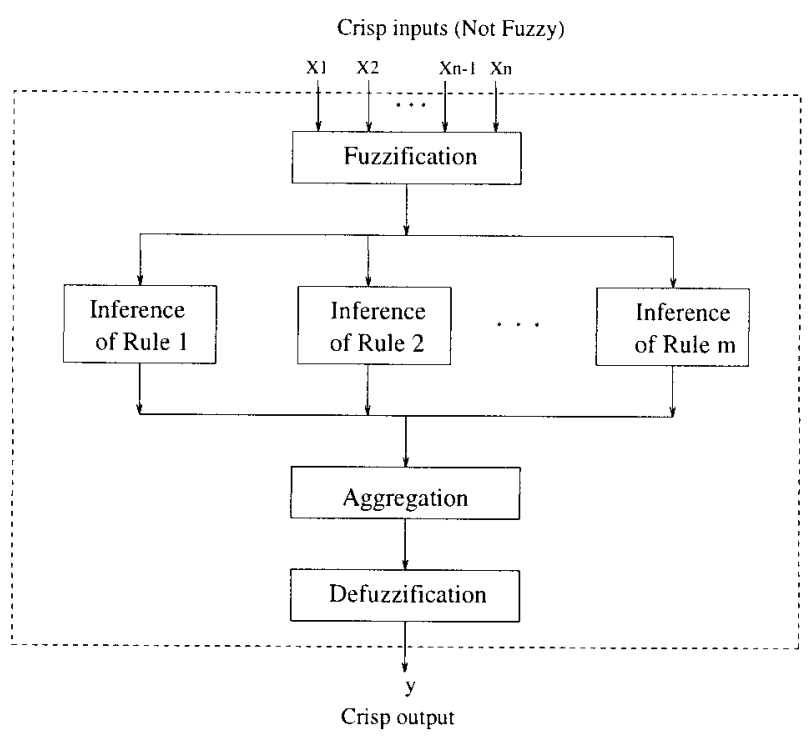

FIG. 1. Block diagram of a general fuzzy logic system. 


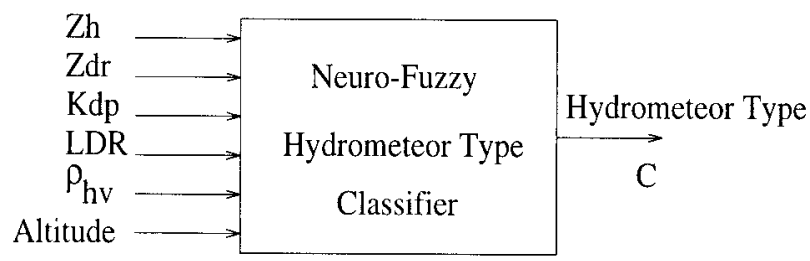

FIG. 2. Block scheme of the fuzzy classifier.

ple lookup table because the radar signature for different hydrometeors is not mutually exclusive and unique. The current state of the art involves the use of several polarimetric data fields and some empirical knowledge to arrive at a decision on the hydrometeor type. This manual procedure is reliable, if it is done by experts, but is very inefficient and cannot process large amounts of radar data in a reasonable time. Therefore, it is important to develop an automatic classification system. Some potential techniques that can be used for automatic hydrometeor classification are (i) decision tree method, (ii)
TABLE 1. Output of the fuzzy classifier system.

\begin{tabular}{lc}
\hline \hline \multicolumn{1}{c}{ Hydrometer type } & Classifier output C \\
\hline Drizzle & 1 \\
Rain & 2 \\
Low-density dry ice crystal & 3 \\
High-density dry ice crystal & 4 \\
Wet ice crystal & 5 \\
Dry graupel & 6 \\
Wet graupel & 7 \\
Small hail & 8 \\
Large hail & 9 \\
Rain + hail & 10 \\
\hline
\end{tabular}

classic statistical decision theory, (iii) neural network techniques, and (iv) fuzzy logic. Among these, the fuzzy logic method is perhaps the best suited for the problem at hand as explained below.

Over the last decade, when polarimetric radar observations became more prevalent, many advances were made in the context of hydrometeor identification. Some of these advances are as follows.

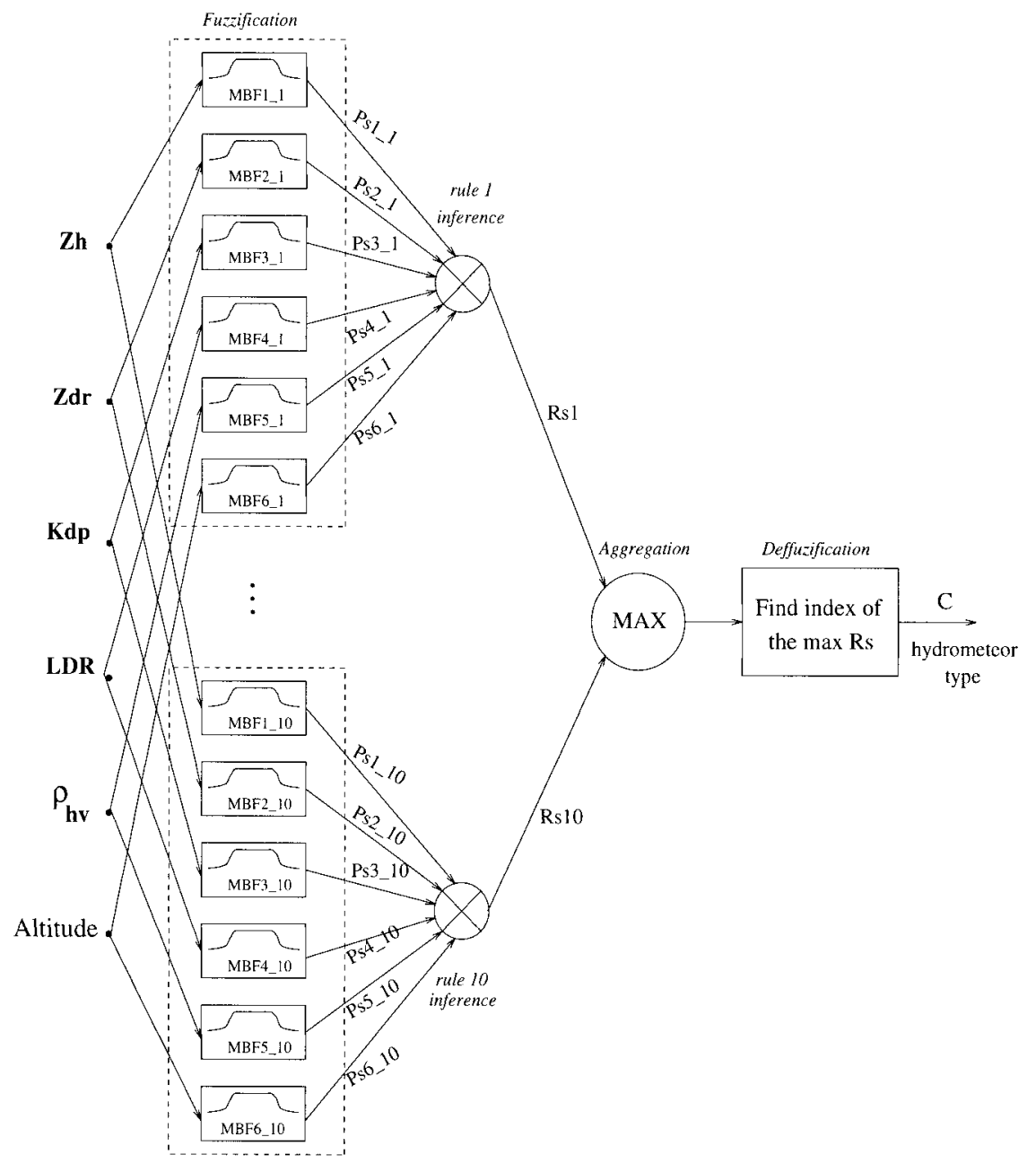

FIG. 3. A fuzzy system for hydrometeor type classification. 


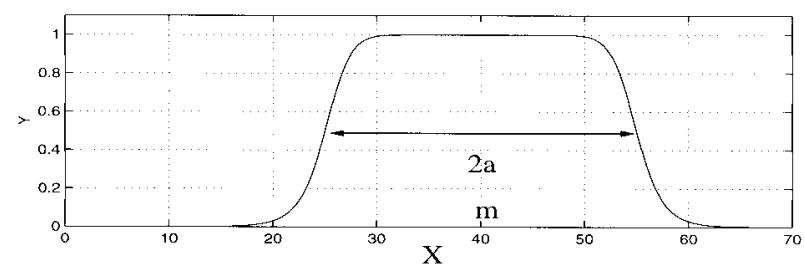

FIG. 4. Beta function.

\section{1) ClassificAtion USING DIFFERENTIAL} $\operatorname{REFLECTIVITY}\left(Z_{\mathrm{DR}}\right)$

Since the introduction of $Z_{\mathrm{DR}}$ measurement for rainfall estimation applications, $Z_{\mathrm{DR}}$ has been used to distinguish between rain and ice, as well as identify other targets. For example, Bringi et al. (1984) utilized the differential reflectivity measurements to detect hail and showed that reliable differentiation between regions of hail and rainfall is possible in convective storms. Hall et al. (1984) used differential reflectivity and reflectivity measurements to identify various hydrometeor types and ground targets.

\section{2) ClassificAtion USING LiNeAR DEPOLARIZATION RATIO}

Bringi et al. (1986) studied the profiles of $Z_{\mathrm{DR}}$, linear depolarization ratio (LDR) and reflectivity at horizontal

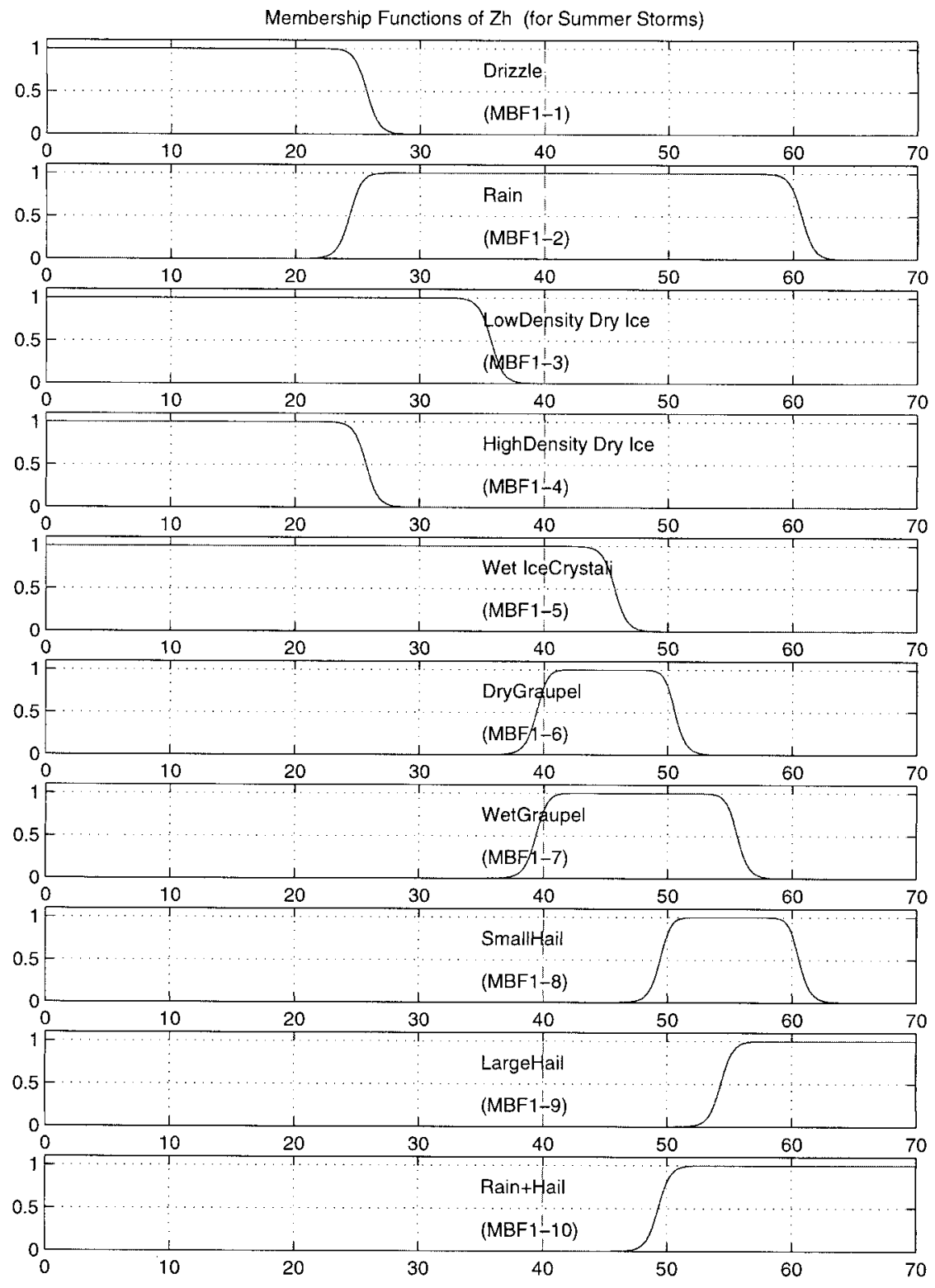

FIG. 5. Membership functions for fuzzy variable $Z_{h}$, and illustration of the fuzzification of $Z_{h}$ to its 10 fuzzy sets. 


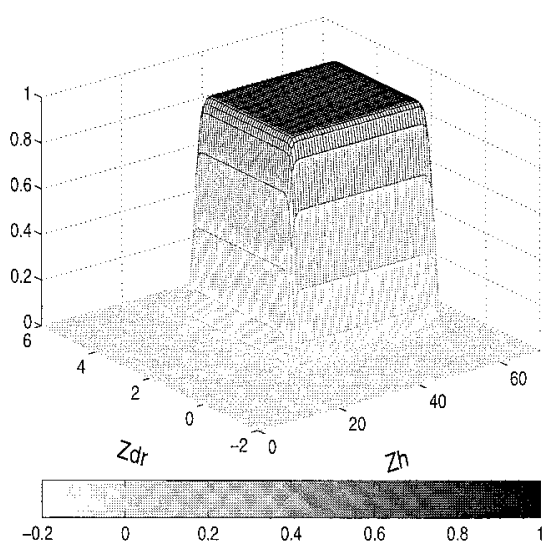

(a)

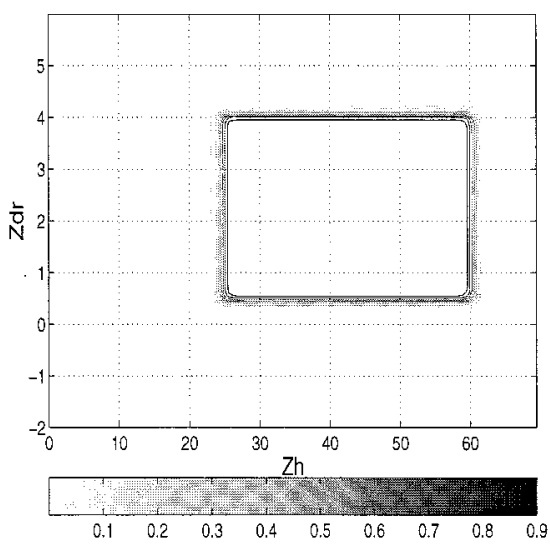

( b )

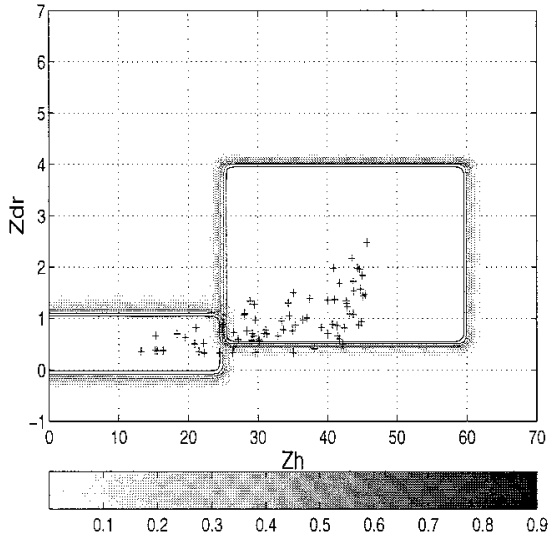

(c)

FIG. 6. (a) The 2D membership function of $Z_{H}$ and $Z_{\mathrm{DR}}$ for rain set, (b) contour of the 2D membership function, and (c) contour of $2 \mathrm{D}$ membership functions of drizzle and rain with scatterplot of $Z_{\mathrm{DR}}$ vs $Z_{H}$ for rain.

polarization $\left(Z_{H}\right)$ through the core of convective storms and found that these three measurements are useful in identifying the graupel region. At the same time, they found that the vertical structure of $Z_{\mathrm{DR}}$ (below the melting level), LDR (above the melting level), and dualfrequency ratio can provide information on hail shaft structure and vertical extent. A fairly detailed study about the vertical profiles of $Z_{H}, Z_{\mathrm{DR}}$, and the dualwavelength ratio in terms of the size, shape, and fall behavior of the hailstones were presented by Aydin et al. (1990).

\section{3) ClassifiCATION USING SPECIFIC DIFFERENTIAL PROPAGATION PHASE $\left(K_{\text {DP }}\right)$ AND COPOLAR CORRELATION COEFFICIENT $\left(\rho_{H V}\right)$}

Straka and Zrnić (1993) examined the specific differential phase, the backscatter differential phase $(\delta)$, $\rho_{H V}$, and $Z_{\mathrm{DR}}$ observed over a severe hailstorm and demonstrated that these three measurements can be used to detect hail, as well as identify and quantify mixed-phase hydrometeors.

\section{4) Classification Using DifFerence REFLECTIVITY $\left(Z_{\mathrm{DP}}\right)$}

Tong et al. (1998) used the difference reflectivity to estimate the fraction of rain and ice in mixed-phase precipitation. The difference reflectivity $Z_{\mathrm{DP}}$ can be estimated from $Z_{H}$ and $Z_{\mathrm{DR}}$.

\section{5) EMPIRICAL ALGORITHM FOR CLASSIFYING HYDROMETEOR TYPES}

Building on the results of hydrometeor classification in the existing literature, Straka and Zrnić (1993), and Höller (1995) described classification schemes to discriminate between the different hydrometeors. They both used the decision tree method in which predefined boundaries were used to define the decision region.

Thus the polarimetric radar signatures of precipitation have shown the potential for hydrometeor classification and has set the foundation for the development of automatic classification procedure using advanced techniques such as a neural network and fuzzy logic. 


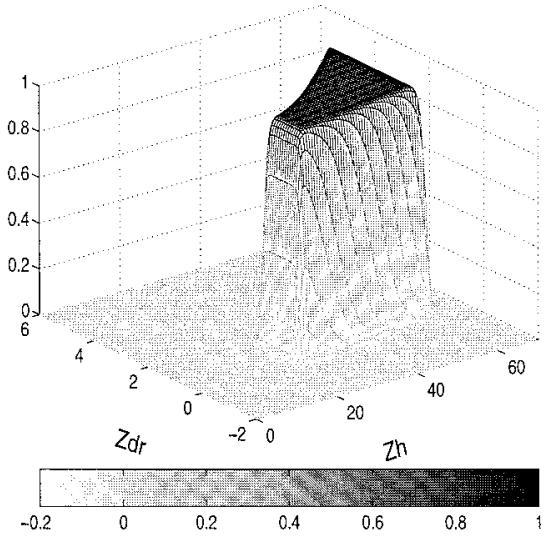

( a )

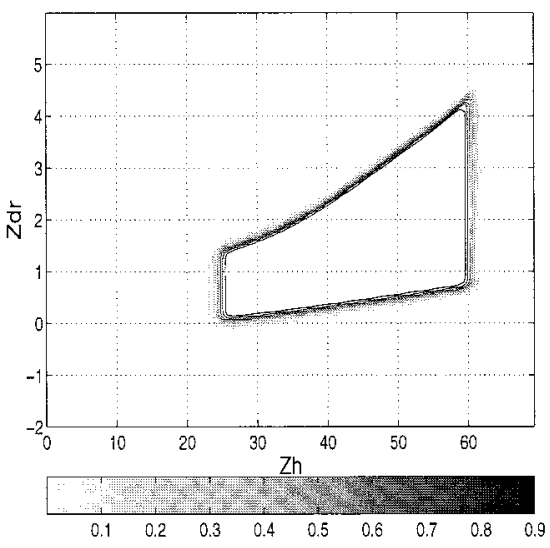

( b )

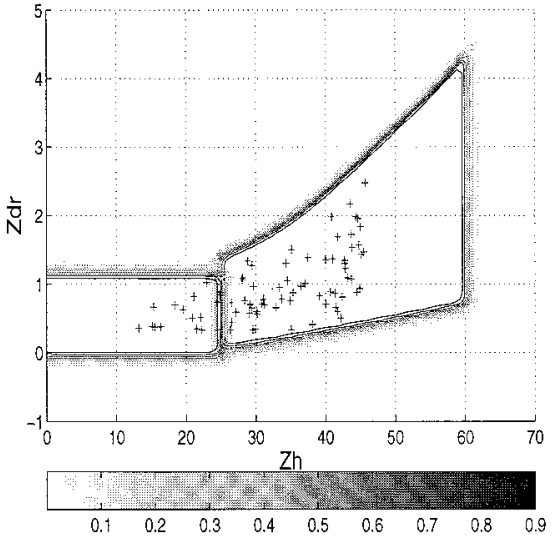

(c)

FIG. 7. (a) Modified 2D membership function of $Z_{H}$ and $Z_{\mathrm{DR}}$ for rain set, (b) contour of the 2D membership function, and (c) scatterplot of $Z_{\mathrm{DR}} \mathrm{vs} Z_{H}$ for rain with the contour of the membership functions.

\section{b. Motivation for using fuzzy logic method}

There are several methods that can be potentially used for hydrometeor identification, such as a decision tree, classic statistical decision theory, neural networks, and fuzzy logic. Fuzzy logic is used in this study for classification because it has many inherent advantages over other methods. Many polarimetric radar measurements lie in a limited measurement space for each hydrometeor type. A decision tree method is essentially based on thresholds and Boolean logic. The decision tree method is inadequate for the hydrometeor classification problem because the measurement set for different hydrometeor is not mutually exclusive. It also does not provide allowance for measurements errors. The fuzzy logic system possesses the ability to reach distinct decisions based on overlapping and "noise contaminated" data.

Statistical decision theory is another potential technique that can be considered for the hydrometeor classification problem. However, statistical models are difficult to construct. For example, the statistical model for the rain identification can be expressed as follows:

$$
\begin{aligned}
& P\left(C=\text { rain } \mid z_{h}, z_{\mathrm{dr}}, k_{\mathrm{dp}}, \mathrm{LDR}, \rho_{h v}\right) \\
& =\frac{f\left(z_{h}, z_{\mathrm{dr}}, k_{\mathrm{dp}}, \mathrm{LDR}, \rho_{h v} \mid C=\text { rain }\right) \times p(C=\text { rain })}{f\left(z_{h}, z_{\mathrm{dr}}, k_{\mathrm{dp}}, \mathrm{LDR}, \rho_{h v}\right)},
\end{aligned}
$$

where $C$ is the hydrometeor type, $P(C=$ rain $)$ is the prior probability of rain, $f\left(z_{h}, z_{\mathrm{dr}}, k_{\mathrm{dp}}, \mathrm{LDR}, \rho_{h v}\right)$ is the joint probability density of the five radar polarimetric parameters, and $f\left(z_{h}, z_{\mathrm{dr}}, k_{\mathrm{dp}}, \mathrm{LDR}, \rho_{h v} \mid C=\right.$ rain $)$ is the joint probability density function of the five polarimetric radar parameters under the condition of rain.

It is very difficult to obtain the prior probability and the probability density functions. However, fuzzy logic uses simple rules to describe the system of interest rather than analytical equations, thus it is easy to implement for hydrometeor classification. Therefore, based on the above reasons as well as other advantages, such as robustness and speed, fuzzy logic method is the best choice for hydrometeor classification. 


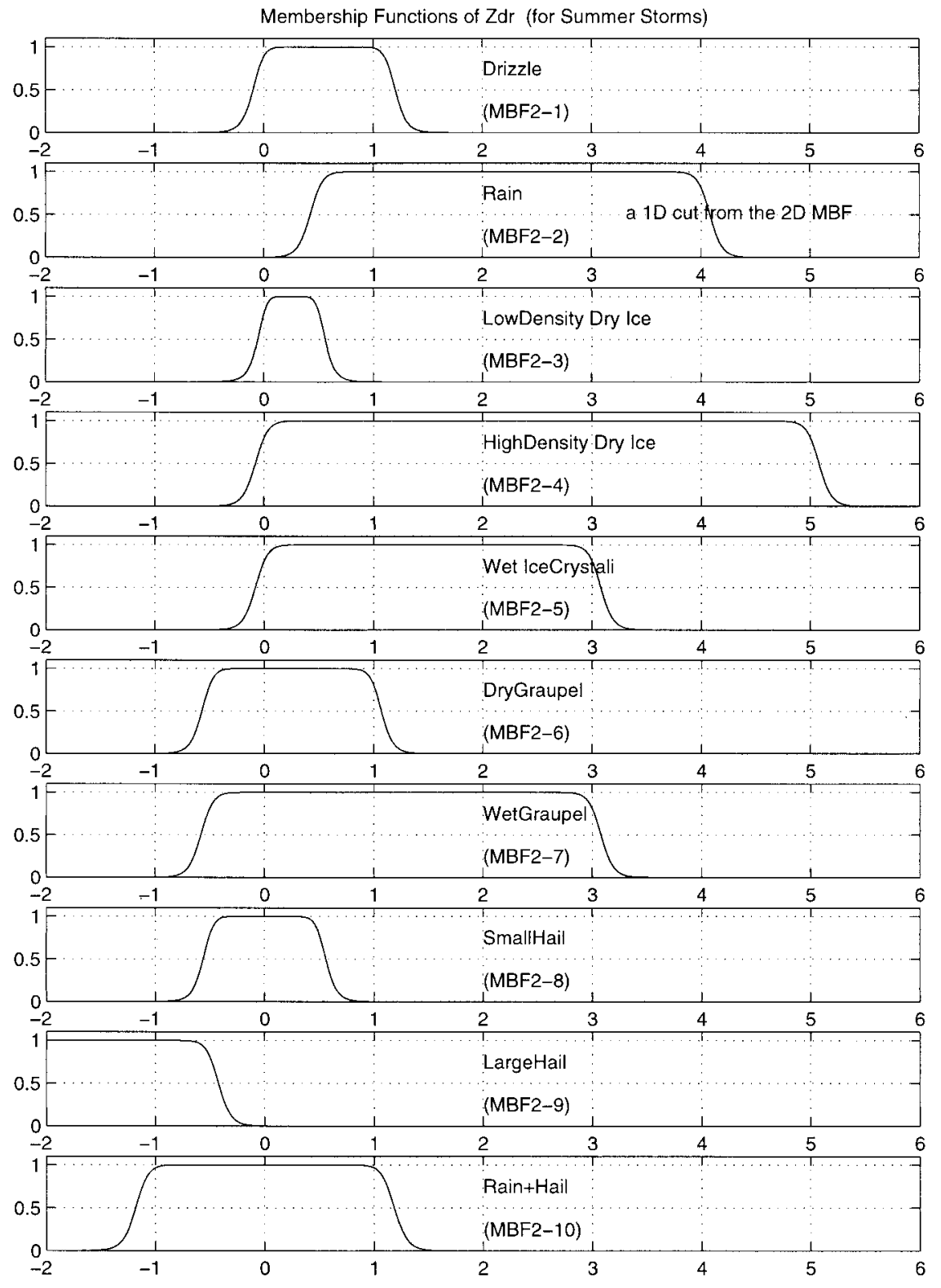

FIG. 8. Fuzzy sets for differential reflectivity $Z_{\mathrm{DR}}$.

\section{c. Advantages of neuro-fuzzy classification system}

In this paper, a neuro-fuzzy system instead of a pure fuzzy logic system is developed for the hydrometeor classification problem because the combination of neural network and fuzzy logic enables the system to learn and improve its performance based on past data. Therefore, the neuro-fuzzy system with the learning capability of neural network and with the advantages of the rulebased fuzzy system can improve the classifier's performance immensely and can provide a mechanism to incorporate past observations into the classification process. Unlike the neural network scheme in which the training essentially builds the system, in a neuro-fuzzy scheme, the system is built by fuzzy logic definitions and then it is refined using "neural network-type training." Therefore, extensive training from the beginning is inappropriate for this system. Future in situ data collection will have an important role to play in refining the system.

The paper is organized as follows. The development of a fuzzy hydrometeor classifier is discussed in section 2. Section 3 describes the neuro-fuzzy hydrometeor classifier, which includes the configuration of the neurofuzzy hydrometeor classifier and the fuzzy set learning algorithm. Finally, the classifier's performance is evaluated using data collected by the Colorado State Uni- 


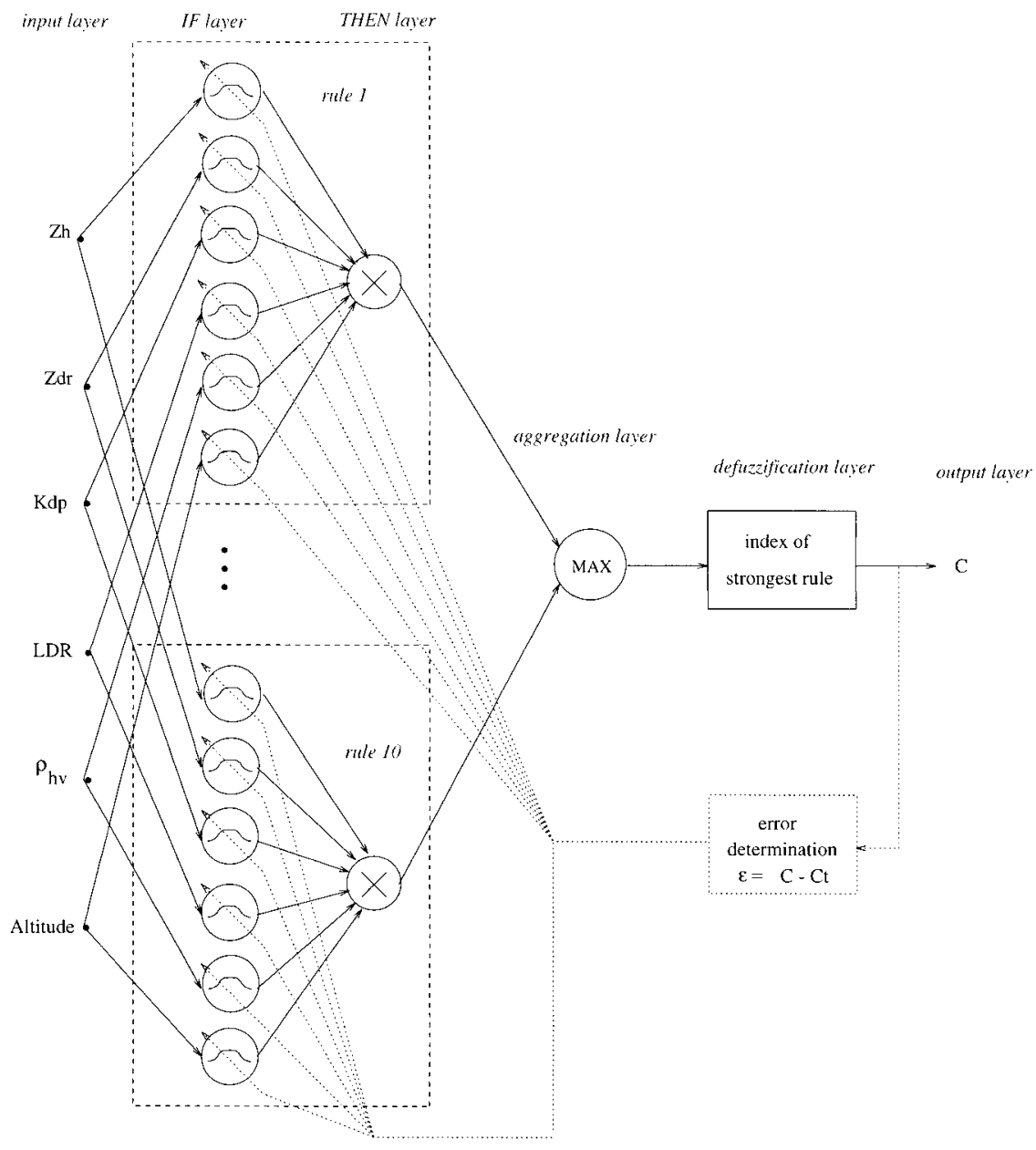

FIG. 9. A neuro-fuzzy system for hydrometeor-type classification.

versity-CHILL radar and in situ observations, and the results are presented in section 4.

\section{Fuzzy logic hydrometeor classifier}

a. Configuration of a general fuzzy logic system

The fuzzy logic system consists of four parts: 1) fuzzification, 2) rule inference, 3) aggregation, and 4) defuzzification (Heske and Heske 1996). The block diagram of a general fuzzy logic system is shown in Fig. 1 , where $x_{1}, x_{2}, \ldots, x_{n}$ stand for $n$ "crisp" (or distinct) inputs and $y$ is the crisp output. The function of the various blocks in the fuzzy logic system are as follows.

\section{1) FuzzificAtion}

The function of the "fuzzification" block is to convert the crisp inputs (or precise measurements) to the fuzzy sets with a corresponding membership degree. A specific crisp input can belong to different fuzzy sets but with different membership degrees (or truth value). The most important component in fuzzification is the mem- bership function, which is used to describe the relationship of the crisp input and the fuzzy sets in the input domain (Zadeh 1983). The definition of membership function is as follows: $\mu_{\mathrm{A}}(x)$ is called membership function of fuzzy set A (for a fuzzy variable $x$ ), whose value is the degree to which $x$ is a member of fuzzy set A.

\section{2) INFERENCE}

In a fuzzy logic system, rules are used to describe linguistically the complex relationship between the input and output fuzzy variables in the form of IF-THEN statements. Typically, the rule is composed of several antecedents in the IF statement and one or several consequents in the THEN statement. The process of deducing the "strength" of these consequents from the strength of the antecedents is called rule inference. The most commonly used inference methods are correlation minimum, correlation product, and MIN-MAX (Heske and Heske 1996). 
TABLE 2. CSU-CHILL radar characteristics.

\begin{tabular}{|c|c|}
\hline \multicolumn{2}{|l|}{ Antenna } \\
\hline Type & $\begin{array}{l}\text { Fully steerable, prime focus para- } \\
\text { bolic reflector }\end{array}$ \\
\hline Size & $8.5 \mathrm{~m}$ \\
\hline Feed & Scalar horn \\
\hline Half-power beamwidth & $1.0^{\circ}$ \\
\hline Gain (directivity) & $45 \mathrm{~dB}$ \\
\hline Sidelobe level & $\geq-27 \mathrm{~dB}$ \\
\hline Cross-pol. level & $\leq-35 \mathrm{~dB}$ \\
\hline Polarization radiated & Horizontal or vertical \\
\hline Scan type & PPI, RHI, sector scan \\
\hline \multicolumn{2}{|l|}{ Transmitter } \\
\hline Type & Klystron, modernized FPS-18 \\
\hline Wavelength & $11 \mathrm{~cm}$ \\
\hline Peak power & $700 \sim 1000 \mathrm{~kW}$ \\
\hline Pulse width & $0.1 \sim 1.0 \mu \mathrm{s}$ in steps of $0.1 \mu \mathrm{s}$ \\
\hline PRT & $800 \sim 2500 \mu \mathrm{s}$ \\
\hline Max unambiguous range & $375 \mathrm{~km}$ \\
\hline Max unambiguous velocity & $\pm 34.4 \mathrm{~m} \mathrm{~s}^{-1}$ \\
\hline \multicolumn{2}{|l|}{ Receiver } \\
\hline Noise figure & $\sim 3.4 \mathrm{~dB}$ \\
\hline Transfer function & Linear \\
\hline Dynamic range & $>85 \mathrm{~dB}$ \\
\hline Min detectable signal & $-114 \mathrm{dBm}(\mathrm{SNR}=0 \mathrm{~dB})$ \\
\hline \multicolumn{2}{|l|}{ Data Acquisition } \\
\hline Signal processor & SP20 made by Lassen Research \\
\hline Number of range gates (bins) & Variable 64-2048 \\
\hline Range gate (bin) spacing & $0.2 \mu \mathrm{s}$ or $1.0 \mu \mathrm{s}$ \\
\hline Sampling rate/avg. opt. & Under micro-code control \\
\hline Video digitizer & $\begin{array}{l}12 \text { bit, in the SP20 input card for } \\
I, Q \text {, and } \log P \text {. }\end{array}$ \\
\hline Time series capability & $\begin{array}{l}\text { Up to } 150 \text { gates with continuous } \\
\text { recording }\end{array}$ \\
\hline \multicolumn{2}{|l|}{ Variables Available } \\
\hline $\begin{array}{l}\text { Reflectivity at } \mathrm{H} \text { and } \mathrm{V} \text { polari } \\
\text { Mean Doppler velocity }(v) \text { an } \\
\text { Differential phase between } \mathrm{H} \\
\text { Copolar correlation coefficien } \\
\text { Doppler spectra from FFT pro } \\
I, Q \text {, and } \log P \text { for every pulse }\end{array}$ & $\begin{array}{l}\text { ations } \\
\text { spectral width }\left(\sigma_{v}\right) \\
\text { and V states }\left(\phi_{\mathrm{dp}}\right) \\
{\left[\left(\rho_{h v}(0)\right]\right.} \\
\text { cessing } \\
\text { in time series mode }\end{array}$ \\
\hline
\end{tabular}

\section{3) Aggregation}

Several rules (instead of a single rule) can be used to describe a fuzzy logic system. This set of rules is called a rulebase. The complete knowledge about a fuzzy model is contained in its rulebase and the membership functions (MBFs). We can use the inference methods to derive the strength of each rule, then the aggregation method can be used to determine an overall fuzzy region. Two commonly used aggregation methods are additive aggregation and MAX Aggregation.

\section{4) DefuzZification}

The output of aggregation process is a fuzzy set, but in many applications (such as hydrometeor classification) it is necessary to find a crisp value that best represents the fuzzy output set, and this process is called defuzzification. Two commonly used defuzzification

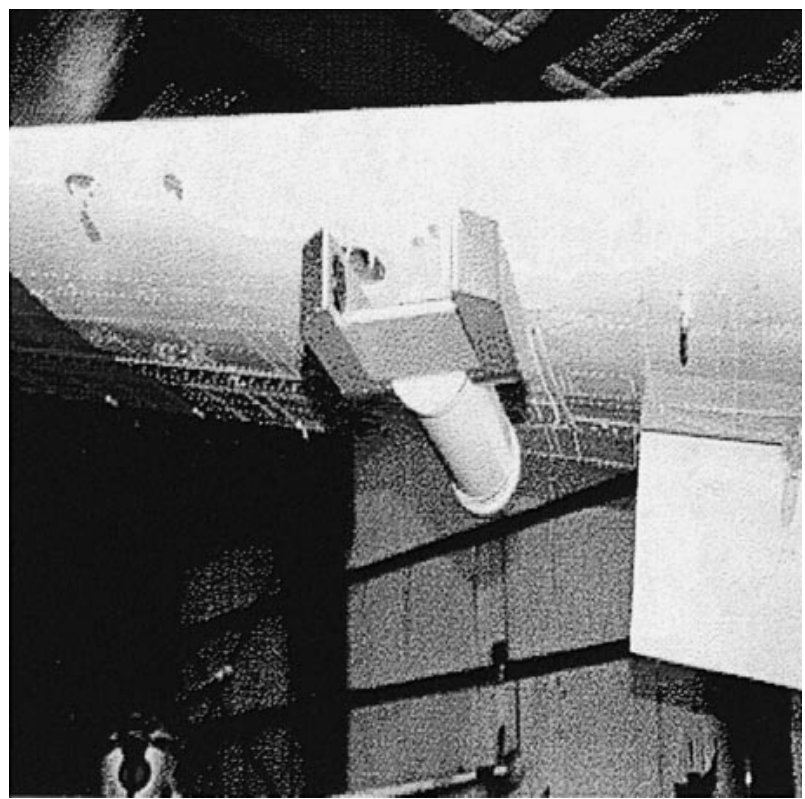

FIG. 10. HVPS probe installed under the right wing of the T-28 aircraft.

methods are the Center of Area (COA) and the Mean of Maximum (MOM).

\section{b. Architecture of a fuzzy hydrometeor classifier}

To implement the hydrometeor classification using fuzzy logic (fuzzy hydrometeor classifier, henceforth referred to as FHC), the four general blocks (fuzzification, IF-THEN rule inference, aggregation, and defuzzification) need to be specified. The block diagram of the FHC is shown in Fig. 2, where $Z_{H}, Z_{\mathrm{DR}}, K_{\mathrm{DP}}, \mathrm{LDR}, \rho_{h v}$, and altitude of the observation $(H)$, are the six inputs, and the hydrometeor class $(C)$ is the output. The FHC will infer the hydrometeor type $C$ based on the rulebase from the six inputs. Table 1 lists the 10 classes used in inference of summer convective storms. The detailed block diagram of the fuzzy hydrometeor classifier is shown in Fig. 3.

\section{c. Classification procedure}

The classification procedure of FHC shown in Fig. 3 can be described as follows. First, the five radar measurements and altitude are fuzzified by using MBFs. There are $10 \mathrm{MBFs}$ for each of the input variables in the system. After fuzzification, the IF-THEN rule inference is carried out based on the rulebase for the classification system. To achieve the total effect of all the rules, rule aggregation is applied. The last step is defuzzification, which can convert aggregation result to a single hydrometeor type. The following provides detailed description of the steps used in the classification process. 

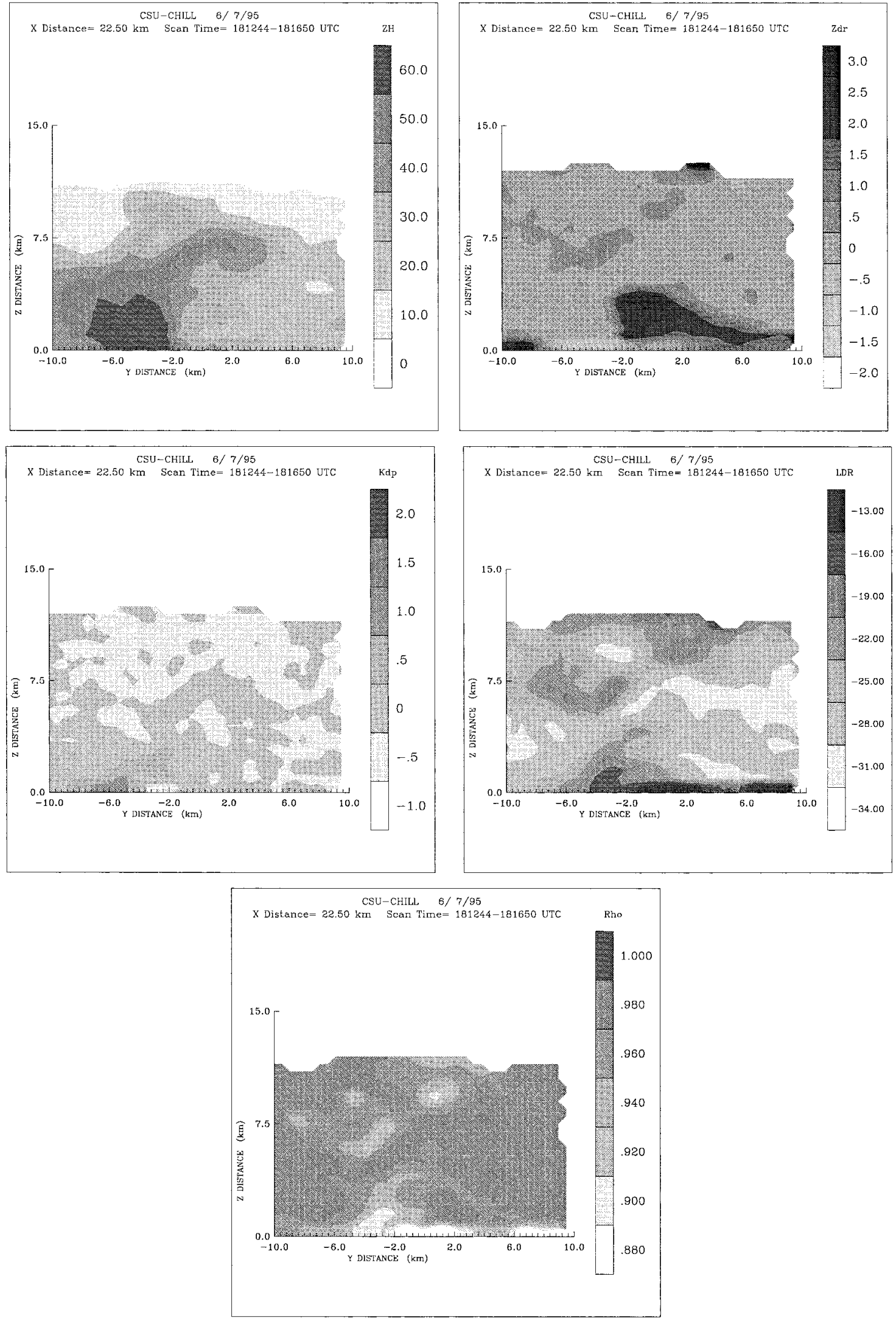

FIG. 11. Radar measurements $Z_{H}, Z_{\mathrm{DR}}, K_{\mathrm{DP}}, \mathrm{LDR}$, and $\rho_{H V}$. 


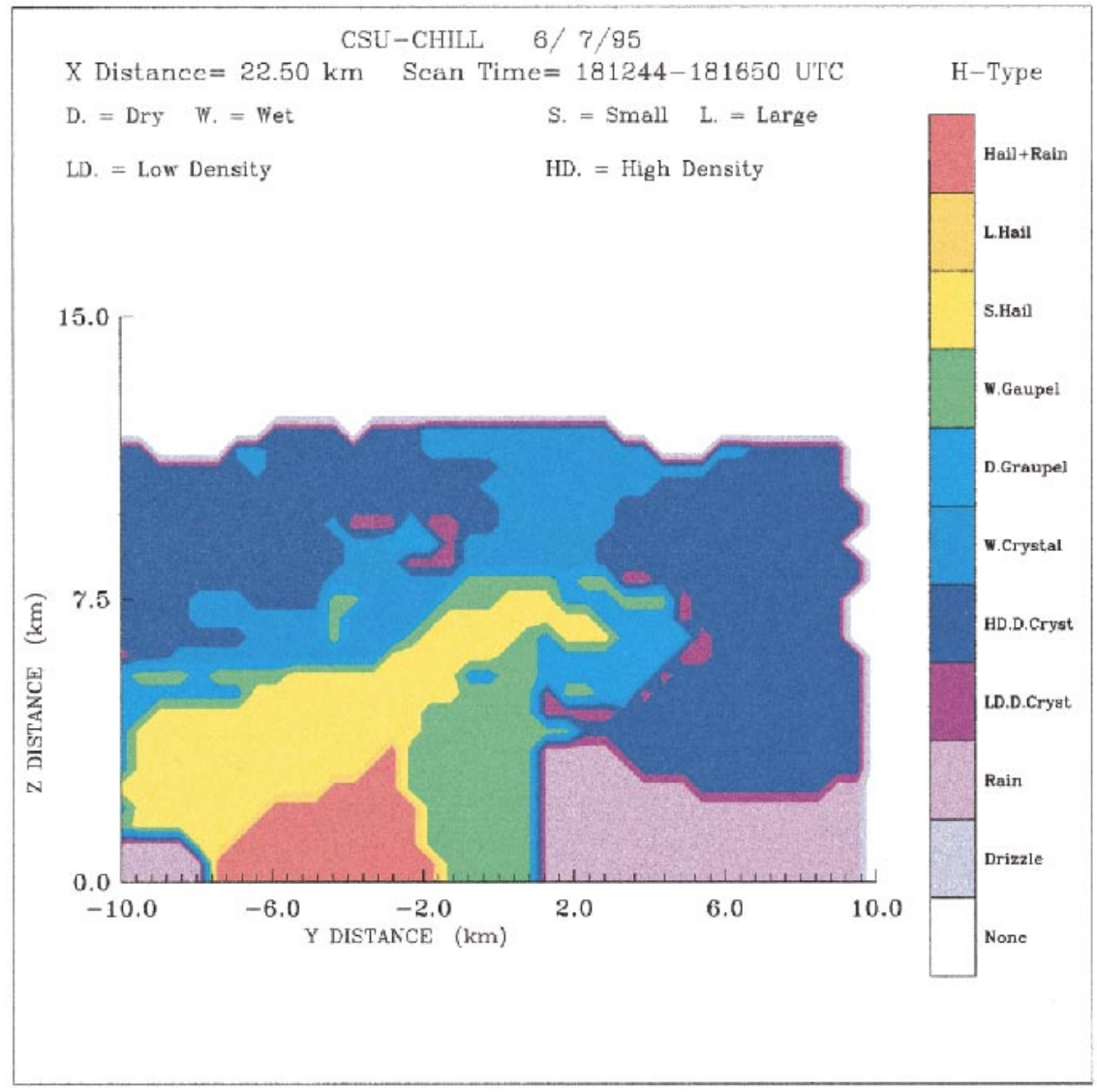

FIG. 12. Hydrometeor type classification result corresponding to the case of 7 Jun 1995.

\section{1) FUZZIFICATION AND MEMBERSHIP FUNCTIONS}

The purpose of fuzzification is to convert the precise input measurements to fuzzy sets with corresponding membership degree. The specification of membership functions is critical to the classification performance. Two different sets of membership functions are used, one for summer storms and the other for winter storms. Ten fuzzy sets corresponding to the 10 hydrometeor types are specified for each of the six input variables for summer storms. Similarly, five fuzzy sets corresponding to the hydrometeor types (viz., drizzle, rain, dry snow, oriented ice crystal, and wet snow) are specified for each of the six input variables for winter snowstorms. Each fuzzy set is represented by a membership function, denoted as $\mathrm{MBF} i_{-j}$, where index $i$ corresponds to the six inputs and index $j$ corresponds to the fuzzy sets. Index $j$ takes values $1-10$ for summer storms and 1-5 for winter snowstorms.

Several functional forms can provide adequate representation of membership functions, such as triangular, trapezoidal, Gaussian shapes, $\mathrm{S}$ and $\mathrm{Z}$ curves, and beta functions. In this study, a beta function is chosen to describe membership function for following reasons. In a hydrometeor classification problem, we expect that most membership functions have a wide flat region in which maximum value is 1 . One hydrometeor type such as rain can have a wide range of reflectivity. In other words, there is no preferred or unique value of reflectivity for rain, but there is a preferred region, such as 25 to $60 \mathrm{dBZ}$. The best MBF to represent this is by means of a flat function over the preferred region that tapers off outside the preferred range. The beta function has the desired characteristics; therefore, it is chosen as the form of the membership functions. In addition, a beta function has a long tail, which improves the robustness of FHC. The derivative of the beta function is continuous, and this feature is useful for automatic adjustment of the parmameters that will be needed for development of neuro-fuzzy system.

The beta membership function is defined as

$$
\operatorname{beta}(x, m, a, b)=\frac{1}{1+\left[\left(\frac{x-m}{a}\right)^{2}\right]^{b}} \text {. }
$$

As seen in (2) there are three parameters that define the shape of a beta function, namely, the center of the function $m$, the width $a$, and the slope $b$ (shown in Fig. 4). Typical one-dimensional membership functions for $Z_{H}$ are shown in Fig. 5 for summer storms and Fig. B4 in appendix B for winter storms. 

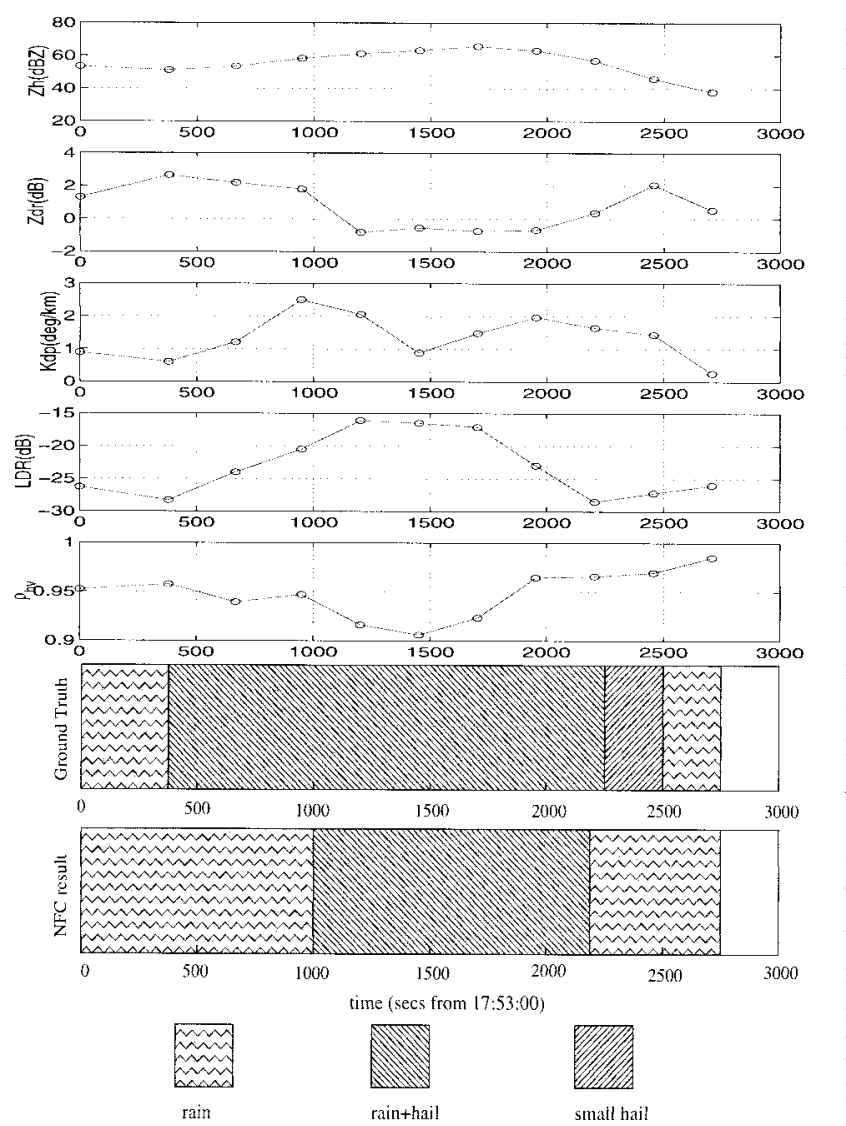

FIG. 13. Comparison classification result from fuzzy logic system with ground truth.

Ten membership functions for $Z_{H}$ are shown in Fig. 5 , which are representations of the 10 fuzzy sets of $Z_{H}$. For each curve, the horizontal axis is the value of $Z_{H}$, and the vertical axis indicates the membership degree of $Z_{H}$ corresponding to that fuzzy set. In a fuzzy logic system, fuzzy sets instead of precise values are used to represent input variables. For example, if we have $Z_{H}$ $=40 \mathrm{dBZ}$, it belongs to the drizzle set with membership degree 0 , to the rain set with membership degree $1, \ldots$, to the dry graupel set with membership degree $0.8, \ldots$, to the rain and hail mixture with membership degree 0 .

If the measurements of $Z_{\mathrm{DR}}$ are physically independent of other radar measurements such as $Z_{H}$, then the one-dimensional membership functions are adequate to represent the fuzzy sets. Multidimensional membership functions can be used to represent combinational fuzzy sets. Let $f_{\text {rainz } z h}$ be the one-dimensional membership function for rain set with respect to input variable $Z_{H}$. Then $f_{\text {rain } z h}$ can be written as

$$
f_{\text {rain_z } h}\left(Z_{H}\right)=\frac{1}{1+\left[\left(\frac{Z_{H}-42.5}{18.17}\right)^{2}\right]^{18.32}} .
$$

Similarly, $f_{\text {rainzzdr }}$, the one-dimensional membership function for rain set with respect to $Z_{\mathrm{DR}}$, can be written as

$$
f_{\text {rain_zdr }}\left(Z_{\mathrm{DR}}\right)=\frac{1}{1+\left[\left(\frac{Z_{\mathrm{DR}}-2.25}{1.83}\right)^{2}\right]^{16.22}} .
$$

If $Z_{H}$ and $Z_{\mathrm{DR}}$ are treated as independent variables for rain, then in a two-dimensional $Z_{H}-Z_{\mathrm{DR}}$ space, the membership function for rain set with respect to $Z_{H}$ and $Z_{\mathrm{DR}}$ can be expressed as the product of $f_{\text {rainzz } z}$ and $f_{\text {rainzzdr }}$ :

$$
f_{\text {rain_z } z \text { zdr }}\left(Z_{H}, Z_{\mathrm{DR}}\right)=f_{\text {rainzzh }}\left(Z_{H}\right) \cdot f_{\text {rainzzdr }}\left(Z_{\mathrm{DR}}\right) .
$$

Here, $f_{\text {rain_z } z \text { zdr }}\left(Z_{H}, Z_{\mathrm{DR}}\right)$ is shown in Fig. 6a and its contours are shown in Fig. 6 b.

However, the radar measurements $Z_{H}$ and $Z_{\mathrm{DR}}$ are not independent in rainfall. For example, the maximum excursion of $Z_{\mathrm{DR}}$ is related to the value of $Z_{H}$ for rain. This feature can be seen from the scatterplot of $Z_{\mathrm{DR}}$ versus $Z_{H}$ from rain data shown in Fig. 6c as "+" (Bringi et al. 1991). All the $\left(Z_{H}, Z_{\mathrm{DR}}\right)$ pairs lie in a small portion of the two-dimensional $\left(Z_{H}, Z_{\mathrm{DR}}\right)$ domain of Fig. $6 \mathrm{a}$. Therefore, we have to modify the 2D membership function given by (5). We can define a new 2D membership functions of rain set with respect to $Z_{H}$ and $Z_{\mathrm{DR}}$ as shown in Fig. 7a; its contours in $Z_{H}-Z_{\mathrm{DR}}$ space are shown in Fig. 7b. In Fig. 7c, we can see that the new two-dimensional membership functions restrict the $Z_{H}-Z_{\mathrm{DR}}$ domain for rain set, incorporating the internal correlation of these two radar measurements. The membership functions of $Z_{\mathrm{DR}}$ for other hydrometeor type sets are represented by using simple one-dimensional membership functions; their waveforms are shown in Fig. 8.

One-dimensional membership functions are used to represent $K_{\mathrm{DP}}$, LDR and $\rho_{H V}$ for all the hydrometeor type fuzzy sets. They are shown in appendix B. It is easy to notice that the slope of membership functions for LDR is small compared to other radar measurement variables; this is based on the fact that LDR has relatively higher measurement error and it is vulnerable to noise contamination. Decreasing the slope is equivalent to increasing the robustness of the parameter. The membership function of altitude is dependent on location and season. The most important parameter here is the melting level. In addition, the altitude of the melting level depends on the season. There are 90 membership functions (60 for summer, 30 for winter). The membership functions will get fine-tuned over time when more in situ data are observed.

\section{2) INFERENCE}

Prior knowledge about the hydrometeor classification problem is incorporated in the fuzzy system in the form of IF-THEN rules and membership functions. The IFTHEN rules for this hydrometeor type classification can be written as follows. 

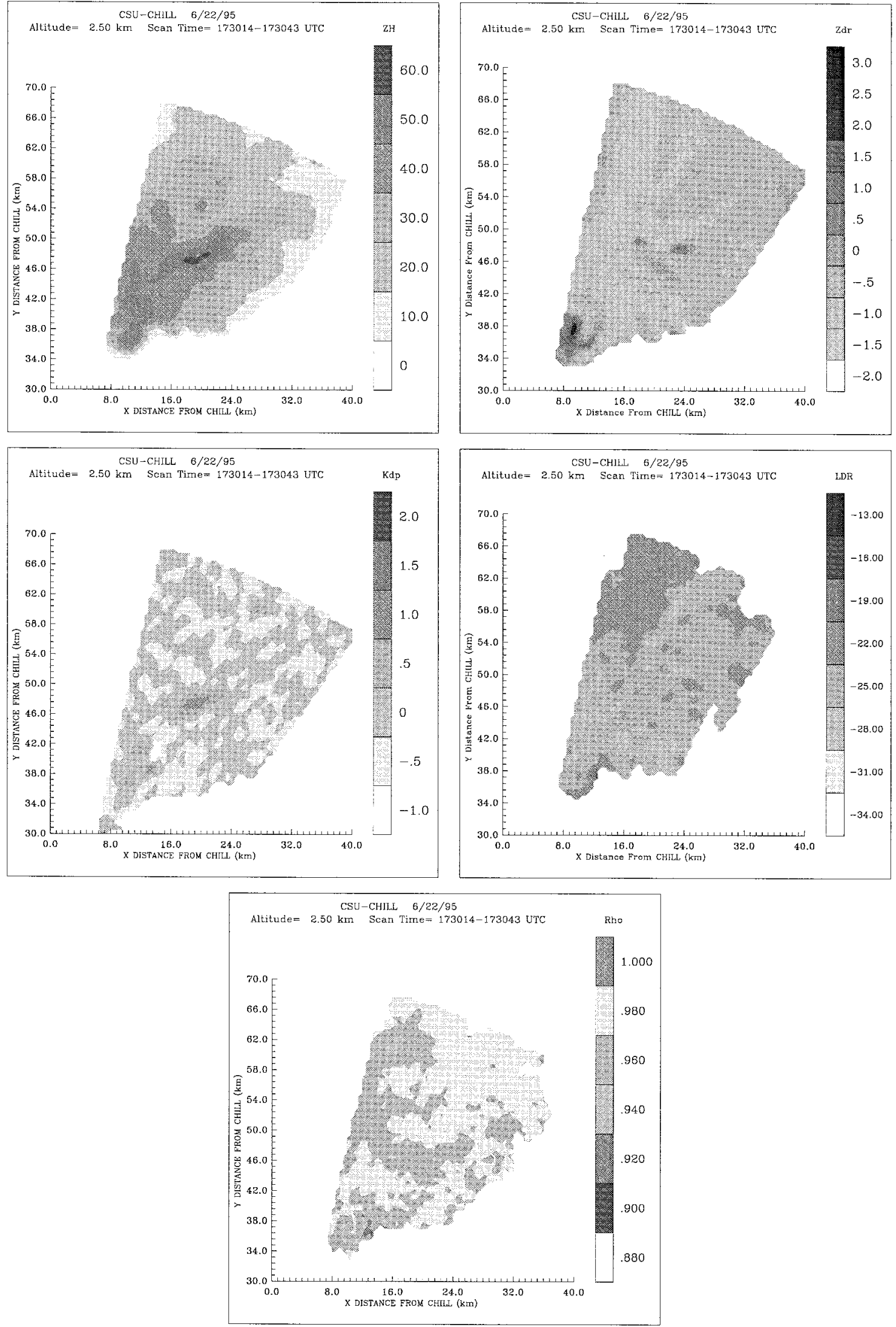

FIG. 14. Radar measurements $Z_{H}, Z_{\mathrm{DR}}, K_{\mathrm{DP}}$, LDR, and $\rho_{H V}$. 


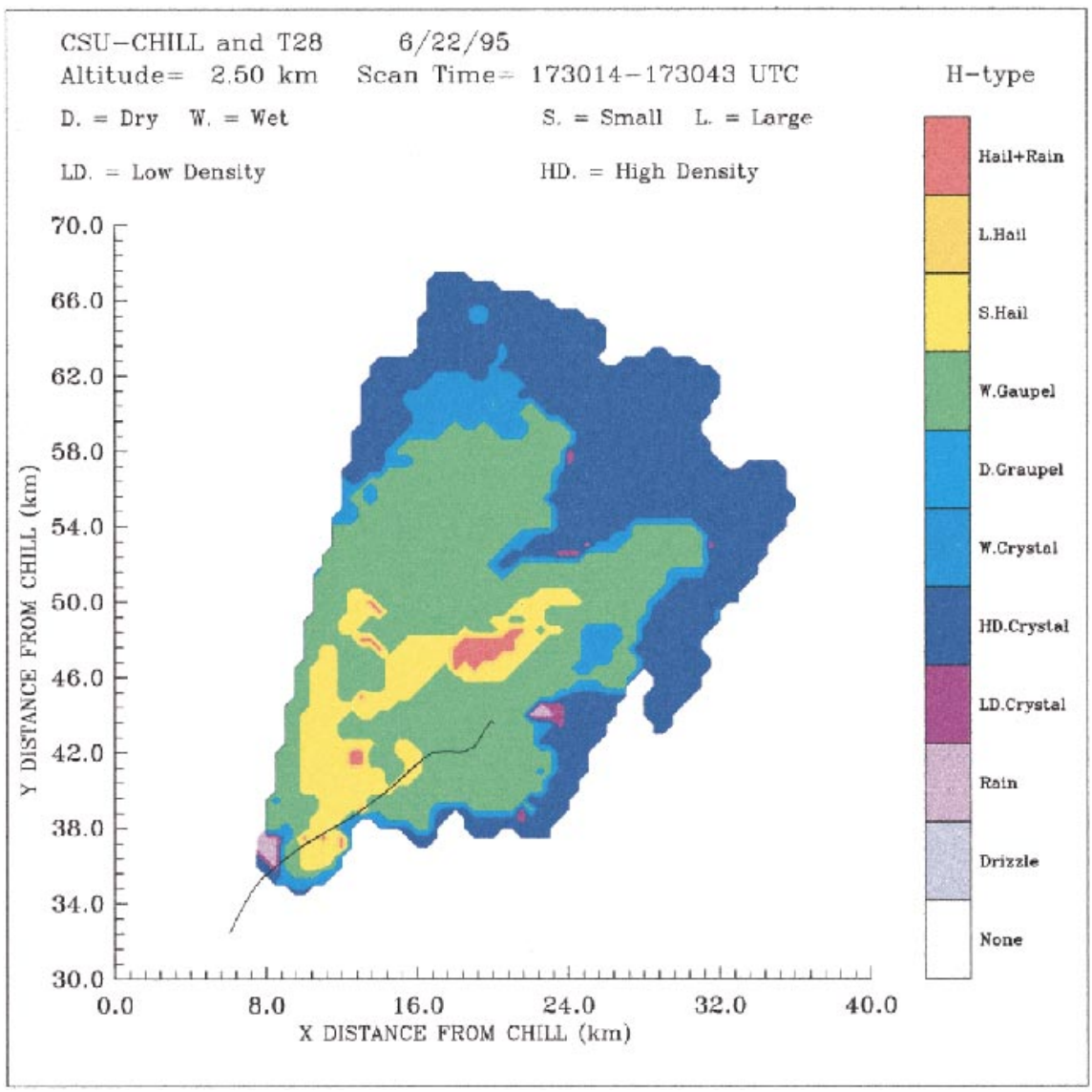

FIG. 15. Hydrometeor type classification result corresponding to the case of 22 Jun 1995.

IF (Zh IS MBF1_j AND Zdr IS MBF2_j AND

\section{Kdp IS MBF3_j AND LDR IS MBF4-j AND}

$\rho_{h v}$ IS MBF5-j AND Height IS MBF6-j)

THEN Hydrometeor Class is $\mathrm{j}$,

where $j=1,2, \ldots, 10$ correspond to the classes listed in Table 1.

The strength for the six antecedent propositions could

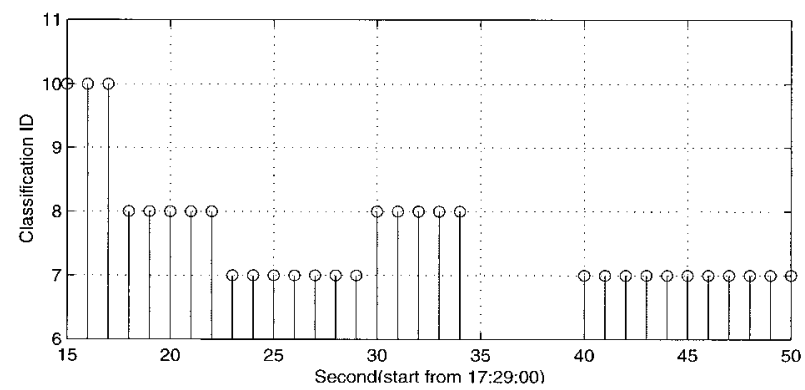

FIG. 16. Classification result along the aircraft track [from $(x: 14.1$ $\mathrm{km}, y: 39.7 \mathrm{~km})$ to $(x: 16.96 \mathrm{~km}, y: 42.01 \mathrm{~km})$ on Fig. 15] during the first penetration in the 22 Jun 1995 storm. be obtained from the fuzzification block as PS $_{i-j}$ where the index $i$ represents the five measurements and the altitude and index $j$ represents the classes. For example, $\mathrm{PS}_{1-2}$ is the strength of reflectivity for rain. In this paper, "product intersection operation" is used to get the strength of the IF-SIDE, and "correlation product" inference method is used to get the rule strength. The truth value of the IF-SIDE is used to scale the consequent fuzzy set. In this case, the strength of the rule is equal to the strength of the IF-SIDE because the output is singleton. Therefore, the strength of rule $j\left(\mathrm{RS}_{j}\right)$ can be obtained as the product of the strength of individual propositions as

$$
\mathrm{RS}_{j}=\prod_{i=1}^{6} \mathrm{PS}_{i-j}
$$

\section{3) Aggregation}

The MAX aggregation method is used to get net fuzzy result from the individual rule inference results. Max aggregation procedures takes only the consequent with the highest truth value. Therefore, the aggregation result 


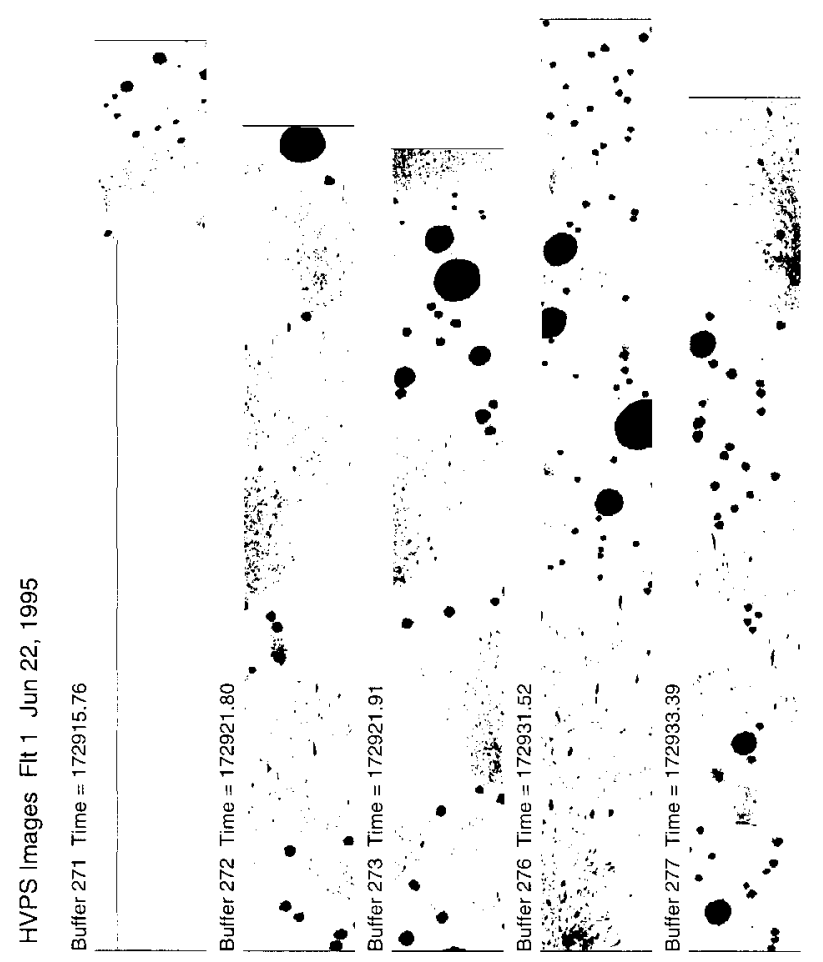

FIG. 17. HVPS images from 1729:15 to $1729: 33$ LT along the aircraft track during the first penetration in 22 Jun 1995 storm.

is the maximum rule strength of the various $\mathrm{RS}_{j}$ 's defined in (6).

\section{4) DefuZZIFICATION}

For the FHC, the output is singleton. A simple method is used to defuzzify the output in order to get a singleton result, namely, the index of the rule with maximum rule strength.

\section{Neuro-fuzzy hydrometeor type classifier}

The performance of the FHC depends critically on the shape of the membership functions. A combination of empirical and theoretical knowledge of current state of the art was used to construct the membership functions. Manually adjusting the functions is tedious and inefficient. It would be very useful to develop a system so that it has the ability to learn from data and adjusts the membership functions automatically. This is achieved by the neuro-fuzzy hydrometeor type classifier developed in this paper.

\section{a. Configuration of neuro-fuzzy hydrometeor type classifiers}

The combinations between neural network and fuzzy logic is a hybrid neuro-fuzzy system. In this system, the fuzzy logic part can be modeled as a multilayer feed-

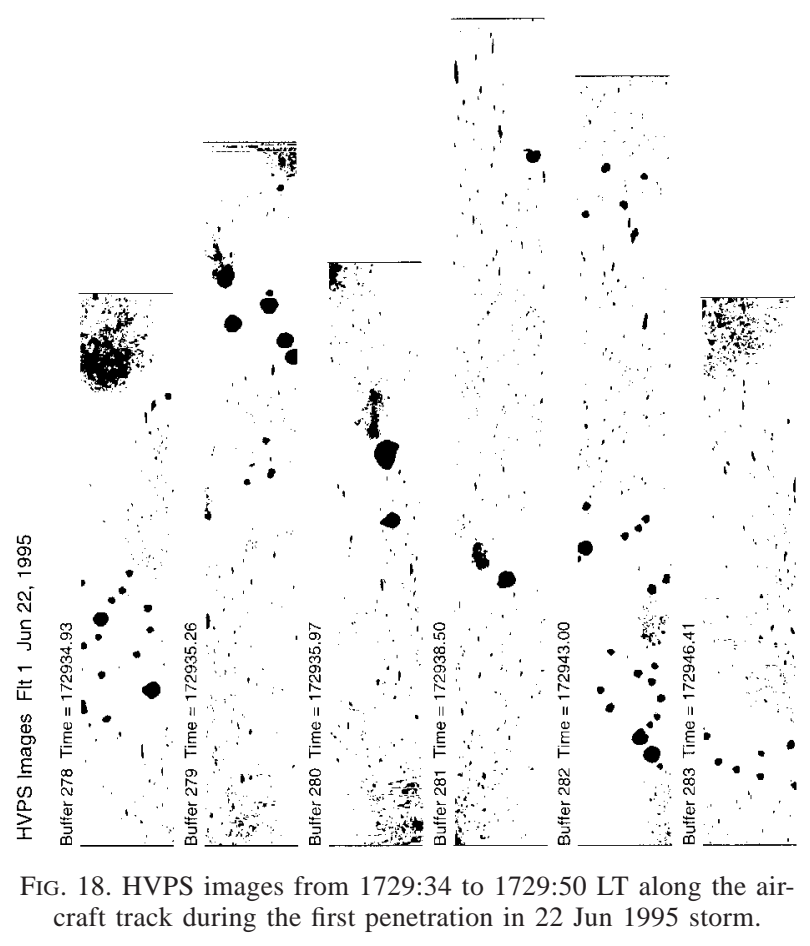

forward neural network, with five layers: 1) the input layer (consisting of input variables), 2) the IF layer (fuzzification layer), 3) the THEN layer (rule inference layer), 4) the aggregation/defuzzification layer, and 5) the output layer. Under this model, the neural network learning algorithms can be used to learn the parameters of the system. One implementation of the neuro-fuzzy hydrometeor classifier (NFHC) is shown in Fig. 9. In Fig. 9 , if we ignore the blocks shown by dotted lines, it is same as the configuration of the FHC described in section 2. The solid lines form the feedforward path, and the dotted lines form the backpropagation path. The misclassification error is backpropagated to the IF layer to adjust the parameters of the membership functions. This is a very effective and efficient procedure to build a good NFHC over time.

\section{b. Fuzzy set learning algorithm}

The learning algorithm for the fuzzy logic system is as follows: let $\mathbf{P}$ be the vector of radar measurements and altitude $\left(Z_{H}, Z_{\mathrm{DR}}, K_{\mathrm{DP}}, \mathrm{LDR}, \rho_{H V}\right.$, and $\left.H\right)$ and let $C_{T}$ be the known class of hydrometeor for this measurement set denoted as target class.

1) Apply the set $\mathbf{P}$ to the FHC and it produces an output $C$.

2) Determine the output error as $\delta=C_{T}-C$.

3 ) Go to (1) if $\delta=0$, otherwise adjust the membership functions according to the procedure given in (4).

4) The adjustment of membership functions is per- 


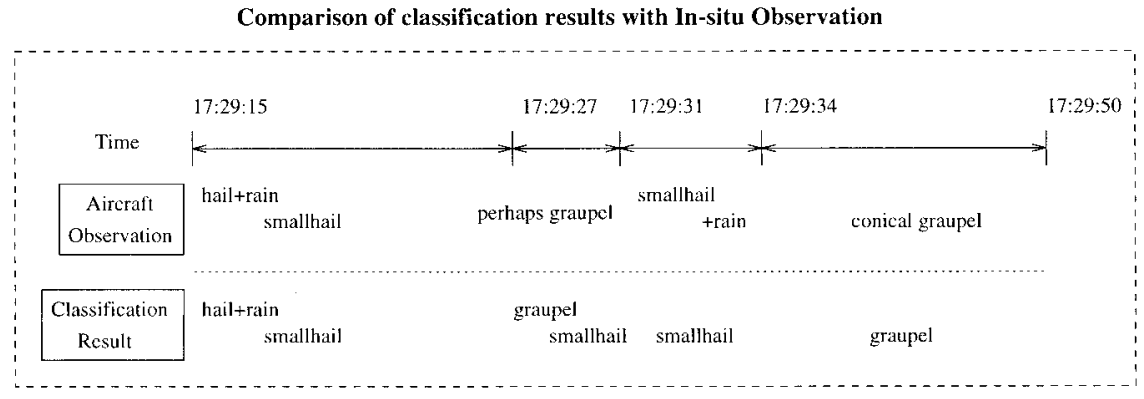

FIG. 19. Comparison of the classification results with in situ observation along the aircraft track during the first penetration in 22 Jun 1995 storm. The time series corresponds to the aircraft track data shown in Fig. 16.

formed only on the fuzzy sets corresponding to class $C_{T}$ and class $C$, which are the target output class and the current output class, respectively, and their rule strength relationship is given by $\mathrm{RS}_{C_{T}}<\mathrm{RS}_{C}$. The adjustment of membership functions should be in the direction that makes $\mathrm{RS}_{C_{T}}>\mathrm{RS}_{C}$. The Gradient descent learning method is used to tune the parameters for the membership functions related to class $C_{T}$ and class $C$. Appendix A describes the details of the procedure used in the adjustment of membership functions.

5) If error goal is not met, go back to step (1), otherwise terminate learning process.

\section{Performance evaluation of the NFHC}

The performance of the hydrometeor classifier is evaluated using radar data from three summer storms, a winter storm, and associated in situ observations. The four storm events are 1) a severe hailstorm on 7 June 1995 , 2) a convective storm on 22 June 1995, 3) a convective storm on 20 June 1995, and 4) a snow event on 18 February 1997.

\section{a. Data sources and instrumentation}

\section{1) CSU-CHILL RADAR}

The radar data used in this study were collected by the CSU-CHILL radar. CSU-CHILL is an S-band, dualpolarization radar, which can measure a full set of polarimetric measurements. The important characteristics of the CSU-CHILL radar relevant to this paper are given in Table 2. Most of the data analyzed in this paper were at ranges less than $70 \mathrm{~km}$ from the radar.

\section{2) IN SITU OBSERVATIONS}

\section{(i) Hail chase van}

An instrumented hail chase van with a roof-mounted net was constructed to intercept the storms. This chase van is equipped with a rain/hail separator and a Young capacitance rain gauge. Hail was collected and quenched in chilled hexane and then stored in dry ice. The hail stones were eventually photographed using digital camera for postanalysis. A detailed description of the hail chase van is given in Hubbert et al. (1998).

\section{(ii) T-28 aircraft}

High-Volume Particle Spectrometer (HVPS) images were collected by using an HVPS probe mounted on the T-28 aircraft, operated by South Dakota School of Mines and Technology. The HVPS is capable of measuring particles size up to $4.5 \mathrm{~cm}$, by taking two-dimensional digital pictures of hydrometeors that pass through a $4.5 \mathrm{~cm} \times 20 \mathrm{~cm}$ plane that is normal to the direction of aircraft flight. This plane is a curtain of light that is projected onto a 256 pixel, linear array that is sampled at a rate proportional to the speed of the aircraft. The pixel spacing in the sample plane is 0.2 $\mathrm{mm}$. As particles pass through the light plane, they create shadows on the linear array that are converted by a one-bit analog-to-digital converter. Thus, as a particle passes through the sample plane, the sequential slides produces a two-dimensional image of the particle. Figure 10 shows the high volume spectrometer installed under the right wing of the T-28.

\section{b. In situ verification of hydrometeor classification}

\section{1) The SEvere haIl StORM ON 7 June 1995}

On 7 June 1995, the CSU-CHILL radar observed a supercell structure, and a chase van with a roofmounted hail collector net was sent to intercept the storm core and collect in situ measurements. The 7 June 1995 storm turned out to be a severe hailstorm. Figure 11 shows the radar measurements $Z_{h}, Z_{\mathrm{dr}}, K_{\mathrm{dp}}$, LDR, and $\rho_{h v}$, and Fig. 12 shows the the classification result from the neuro-fuzzy classification system. We can see from the hydrometeor classification result that the hail and rain mixture, wet graupel, and rain are found on the ground as well as at low altitude, whereas ice crystals were inferred at high altitude. The vertical 

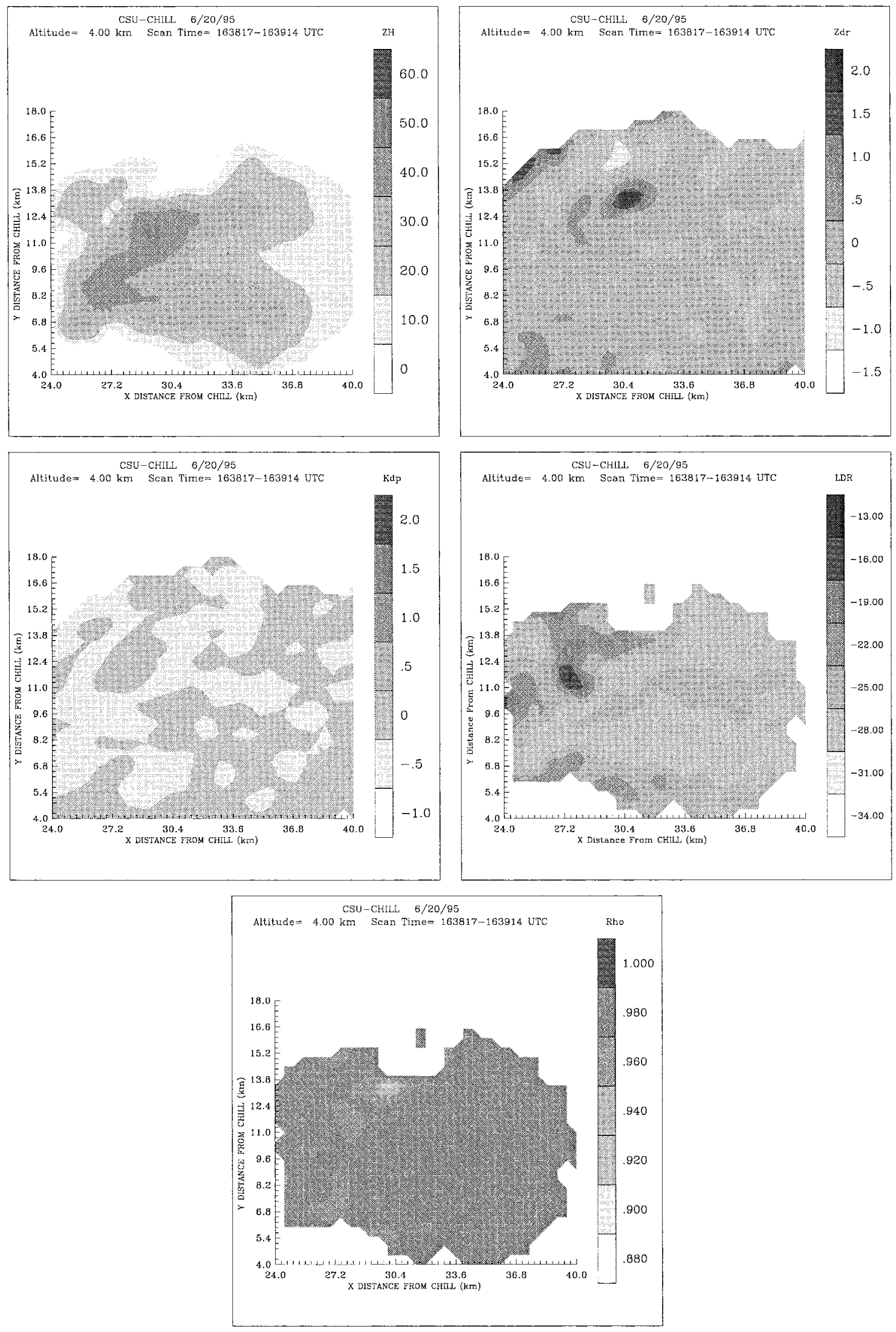

FIG. 20. Radar measurements of $Z_{H}, Z_{\mathrm{DR}}, K_{\mathrm{DP}}, \mathrm{LDR}$, and $\rho_{H V}$. 


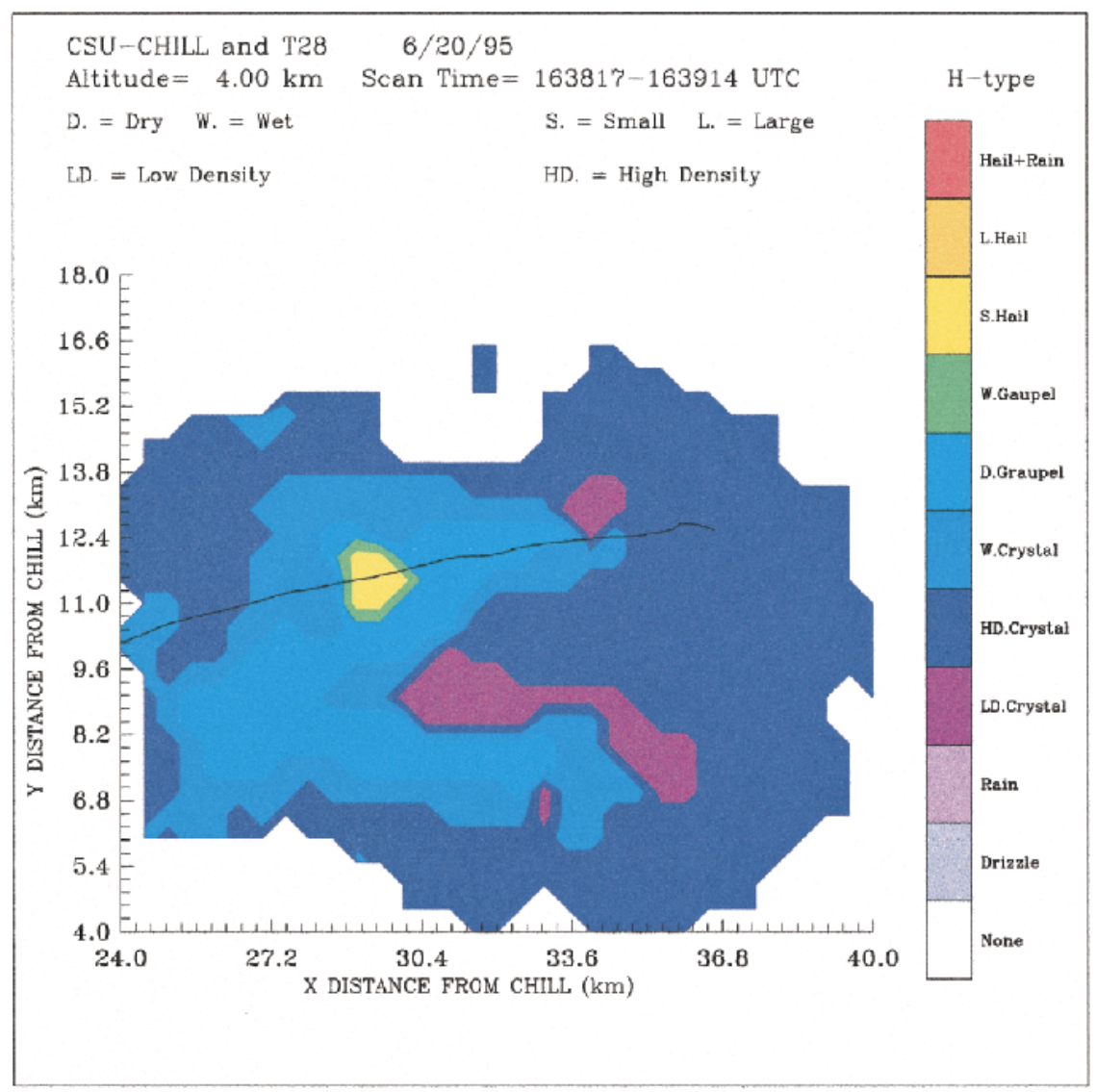

FIG. 21. Hydrometeor-type classification result corresponding to the case of 20 Jun 1995.

structure of the storm can be seen fairly well from the classification result. The in situ ground observations were consistent with the result of the hydrometeor classifier. The hail chase van collected some hailstones and also observed rain mixed within the storm. The in situ ground observations for this case are given in Hubbert et al. (1998); they have presented detailed dual-Doppler analysis of this case. The fuzzy classification results agree very well with inference

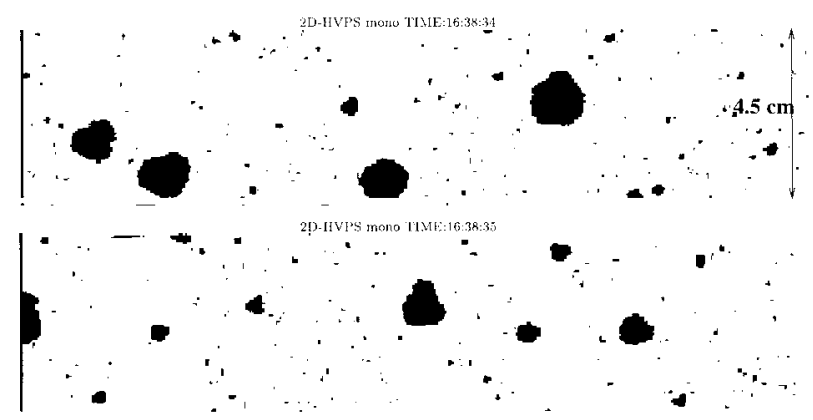

FIG. 22. HVPS images of hydrometeors at 1638:34 UTC in the 20 Jun 1995 storm. The aircraft was located at $x=30.33 \mathrm{~km}, y$ $=11.80 \mathrm{~km}$ with respect to the radar (see Fig. 21) during that time. of Hubbert et al. (1998). Figure 13 shows the time series of the measurements at the hail chase van location $(y=-4.0 \mathrm{~km})$ for $50 \mathrm{~min}$. Figure 13 also shows the hydrometeor classification inferred by the hydrometeor classification system, and the "ground truth" observed by the hail chase van. Note in Fig. 13 that the automatic classification result agrees fairly well within the limits of comparison between radar and ground observations.

\section{2) The COnVective StORM ON 22 June 1995}

A severe hailstorm occurred on 22 June 1995 near Fort Collins, Colorado. This storm grew to a height of $12.5 \mathrm{~km}$ and upon collapsing produced heavy rain and hail of maximum sizes $3-4 \mathrm{~cm}$. The intense part of the storm was located at a distance of $45-50 \mathrm{~km}$ to the northeast of the CSU-CHILL radar around 1730:29 local time (LT). The radar continuously scanned the storm approximately with 2-min resolution for about an hour. At the same time the T-28 aircraft made several penetrations through the storm, collecting samples of hydrometeors. The flights were at altitudes between 2.5 and $3.5 \mathrm{~km}$ above ground level to collect data in small hail region. The storm was characterized by 
(a)

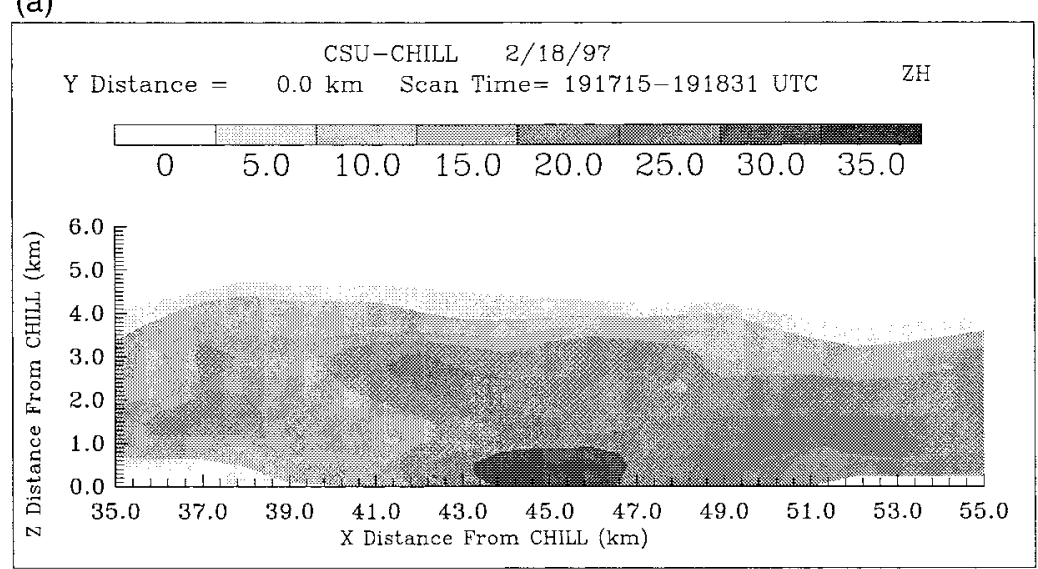

(b)

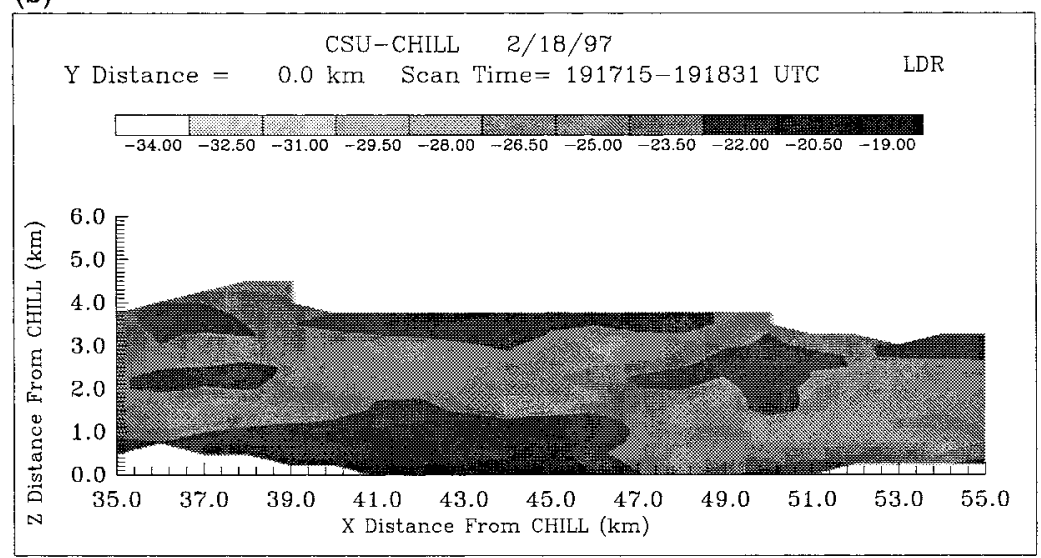

(c)

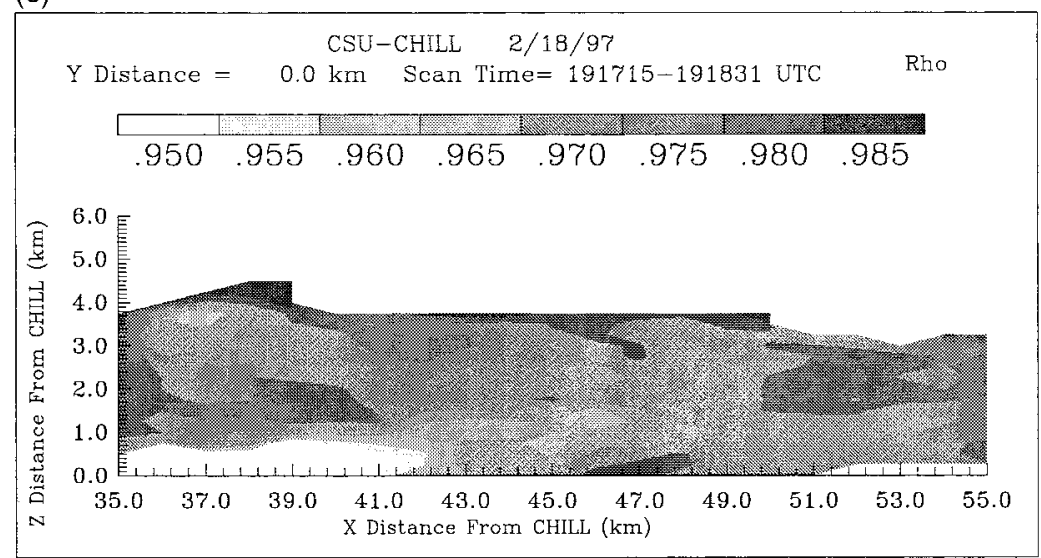

FIG. 23. Radar measurements (a) $Z_{H}$, (b) LDR, and (c) $\rho_{h v}$ for the storm on $18 \mathrm{Feb}$ 1997.

heavy rain mixed with hail. A constant altitude plan position indicator (CAPPI) of the radar measurements $Z_{h}, Z_{\mathrm{dr}}, K_{\mathrm{dp}}, \mathrm{LDR}$, and $\rho_{h v}$ at the height of the aircraft is shown in Fig. 14. Figure 15 shows the automatic hydrometeor classification result. The solid line on Fig.
15 is the flight track of T-28 aircraft. As seen in Fig. 15 the T-28 track was mostly in the region of small hail and graupel. Figure 16 shows time series of automatic hydrometeor classification encountered along the T-28 flight penetration shown in Fig. 15. Note here 


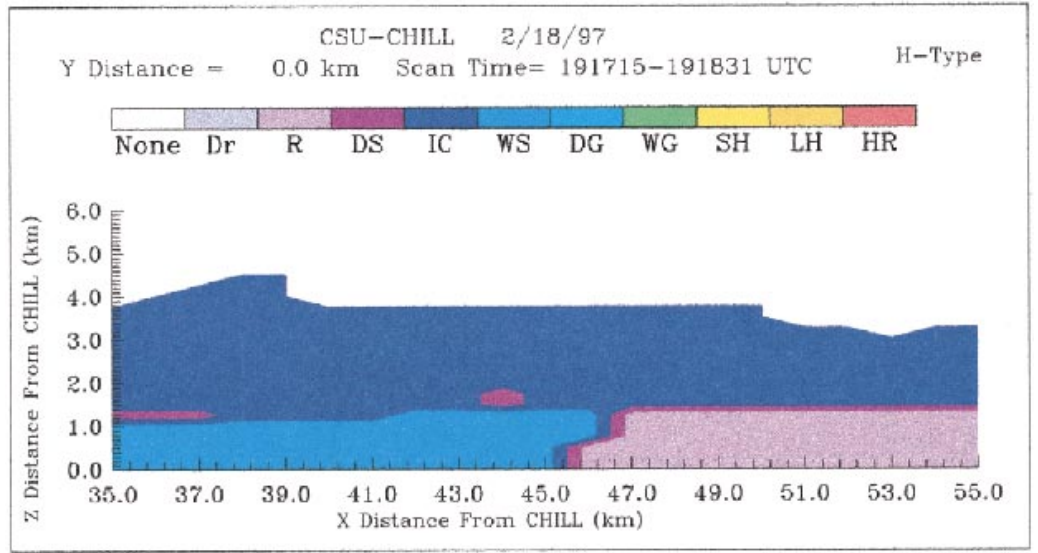

FIG. 24. Hydrometeor-type classification result. (DR, drizzle; R, rain; DS, dry snow; IC, oriented ice crystal; WS, wet snow; DG, dry graupel; WG, wet graupel; SH, small hail; LH, large hail; and HR, mixture of hail and rain.)

that the time series correspond to the distance along the aircraft track [from $(x: 14.1 \mathrm{~km}, y: 39.7 \mathrm{~km})$ to $(x$ : $16.96 \mathrm{~km}, y: 42.01 \mathrm{~km})]$. Figures 17 and 18 show sample HVPS images for the data shown in Fig. 16. Figure 19 shows the comparison of automatic hydrometeor classification and in situ observations from T-28 HVPS data. From Fig. 19, we can see fairly good agreement between automatic classification and in situ observations.

\section{3) The COnVective Storm On 20 June 1995}

On 20 June 1995, the CSU-CHILL radar observed a storm cell that formed $20 \mathrm{~km}$ east of the radar. A T-28 aircraft carrying an HVPS probe penetrated through the core of the storm to collect in situ observations. Most of the aircraft flights through the storm were at a constant altitude of $4 \mathrm{~km}$ above ground. During the flight, the HVPS collected samples of hydrometeors along the path. Figure 20 shows a CAPPI of the radar measurements at an altitude of $4 \mathrm{~km}$ (radar scan time is from 1638:17 to $1639: 14$ UTC). The five radar polarimetric fields are shown in Fig. 20, and the hydrometeor classification result is shown in Fig. 21. The solid line is the T-28 aircraft track. In Fig. 21, note that the aircraft tracks are in predominantly graupel region and a region of small hail. This inference agrees very well with the T-28 in situ aircraft observations obtained from the HVPS probe. Sample images of hydrometeors from HVPS for the flight at 1638:34 UTC are shown in Fig. 22 , the corresponding T-28 aircraft location is at 30.33 $\mathrm{km}$ in the $x$ direction and $11.80 \mathrm{~km}$ in the $y$ direction with respect to the location of the CSU-CHILL radar. The presence of conical graupel particles is seen in the images.

\section{4) The SNOW STORM ON 18 FEBRUARY 1997}

On 18 February, there was a light snow event in the vicinity of the CSU-CHILL radar. Figures 23 and 24 show a vertical section of the CSU-CHILL radar measurements through this storm. The radar measurements of $Z_{H}$, LDR and $\rho_{H V}$ and the hydrometeor classification result are shown in Figs. 23 and 24. The hydrometeor classification indicates wet snow below $1 \mathrm{~km}$, and dry snow and oriented ice crystal above $1 \mathrm{~km}$. We can see a transition from rain to snow on the ground. This feature of rain-to-snow transition was observed on the ground in excellent agreement with radar-based inferences.

\section{Summary and conclusions}

Polarimetric radars have been used for discriminating water and ice regions, detecting ice-crystal and hail regions in storms. In this paper, we have developed a comprehensive automatic classification system using fuzzy logic and neuro-fuzzy network to classify the hydrometeors in storms. The fuzzy logic and neurofuzzy system developed in this work are robust and are not affected by measurement errors. The hydrometeor classifier has been applied to radar data and successfully compared against in situ measurements. The fuzzy logic classification is currently being implemented in the product display in real time in the CSU-CHILL radar. Similar to any newly introduced systems, the fuzzy logic and neuro-fuzzy system will be evaluated, fine-tuned, and improved over time when more observations become available. However, the basic frame work is very conducive to improvement and adjustment. The neuro-fuzzy system can adjust the parameters of the basic fuzzy logic system very efficiently. 
Acknowledgments. This research was supported by the CSU-CHILL radar facility (supported by NSF/ATM9500108 and the state of Colorado), the National Science Foundation (ATM-9413453), and the NASA/ TRMM program. The authors are grateful for the helpful insights provided by Professor Bringi of Colorado State University, and the support from the T-28 staff at SDSMXT.

\section{APPENDIX A}

\section{Adjustment of Membership Function}

(i) From the set of $\mathrm{MBFi}_{-} C_{T}(i \in[1,6])$, find the MBF with the smallest truth degree:

$$
\mathrm{PS}_{k_{-} C_{T}}<\mathrm{PS}_{i_{-} C_{T}} \text {, where } i \in[1,6] \text {. }
$$

For the membership function $\mathrm{MBF}_{k-C_{T}}$, determine the delta values for its parameters $m, a, b$ :

$$
\begin{array}{ll}
\delta_{m} & =l_{m}(-1)\left(\frac{\partial \mathrm{RS}_{C_{T}}}{\partial \mathrm{PS}_{k_{-} C_{T}}}\right)\left(\frac{\partial \mathrm{PS}_{k_{-} C_{T}}}{\partial m}\right), \\
\delta_{a} & =l_{a}(-1)\left(\frac{\partial \mathrm{RS}_{C_{T}}}{\partial \mathrm{PS}_{k_{-} C_{T}}}\right)\left(\frac{\partial \mathrm{PS}_{k_{-} C_{T}}}{\partial a}\right), \text { and } \\
\delta_{b} & =l_{b}(-1)\left(\frac{\partial \mathrm{RS}_{C_{T}}}{\partial \mathrm{PS}_{k_{-} C_{T}}}\right)\left(\frac{\partial \mathrm{PS}}{\partial b}\right),
\end{array}
$$

where $l_{m}, l_{a}$, and $l_{b}$ are the learning rate for the three parameters $m, a, b ; \mathrm{RS}_{C_{T}}$ is the rule strength for rule $C_{T}$, and the derivatives for $\partial \mathrm{PS}_{k_{c}} / \partial m, \partial \mathrm{PS}{ }_{k_{C}} / \partial a$, and $\partial \mathrm{PS}_{k_{C_{T}}} / \partial b$ can be obtained by the following equations:

$$
\begin{aligned}
\frac{\partial \mathrm{PS}_{k_{-} C_{T}}}{\partial m}= & \left(\mathrm{PS}_{k_{-} C_{T}}\right)^{2} \frac{2 b}{a}\left[\left(\frac{x_{k}-m}{a}\right)^{2 b+1}\right], \\
\frac{\partial \mathrm{PS}_{k_{-} C_{T}}}{\partial a}= & \left(\mathrm{PS}_{k_{-} C_{T}}\right)^{2} \frac{2 b}{a}\left[\left(\frac{x_{k}-m}{a}\right)^{2}\right]^{b}, \text { and } \\
\frac{\partial \mathrm{PS}_{k_{-} C_{T}}}{\partial b}= & (-1)\left(\mathrm{PS}_{k_{-} C_{T}}\right)^{2}\left[\left(\frac{x_{k}-m}{a}\right)^{2}\right]^{b} \\
& \times \log \left[\left(\frac{x_{k}-m}{a}\right)^{2}\right]^{b}
\end{aligned}
$$

where $x_{k}$ is the $k$ th crisp input variable. Note that these equations are based on one-dimensional membership functions. As for two-dimensional membership functions, we can get similar derivative expression by converting two-dimensional membership functions to onedimensional membership functions.

After having all these delta values, the three parameters in the membership function can be updated as follows:

$$
\begin{aligned}
& m^{\text {new }}=m^{\text {old }}+\delta_{m}, \\
& a^{\text {new }}=a^{\text {old }}+\delta_{a}, \quad \text { and } \\
& b^{\text {new }}=b^{\text {old }}+\delta_{b} .
\end{aligned}
$$

(ii) Repeat the same procedure as (i) for the membership functions related to the current output class $C$. The updating of membership functions for class $C$ is performed in the same way, but in the direction of decreasing $\mathrm{RS}_{C}$. 


\section{APPENDIX B}

\section{Membership Functions}

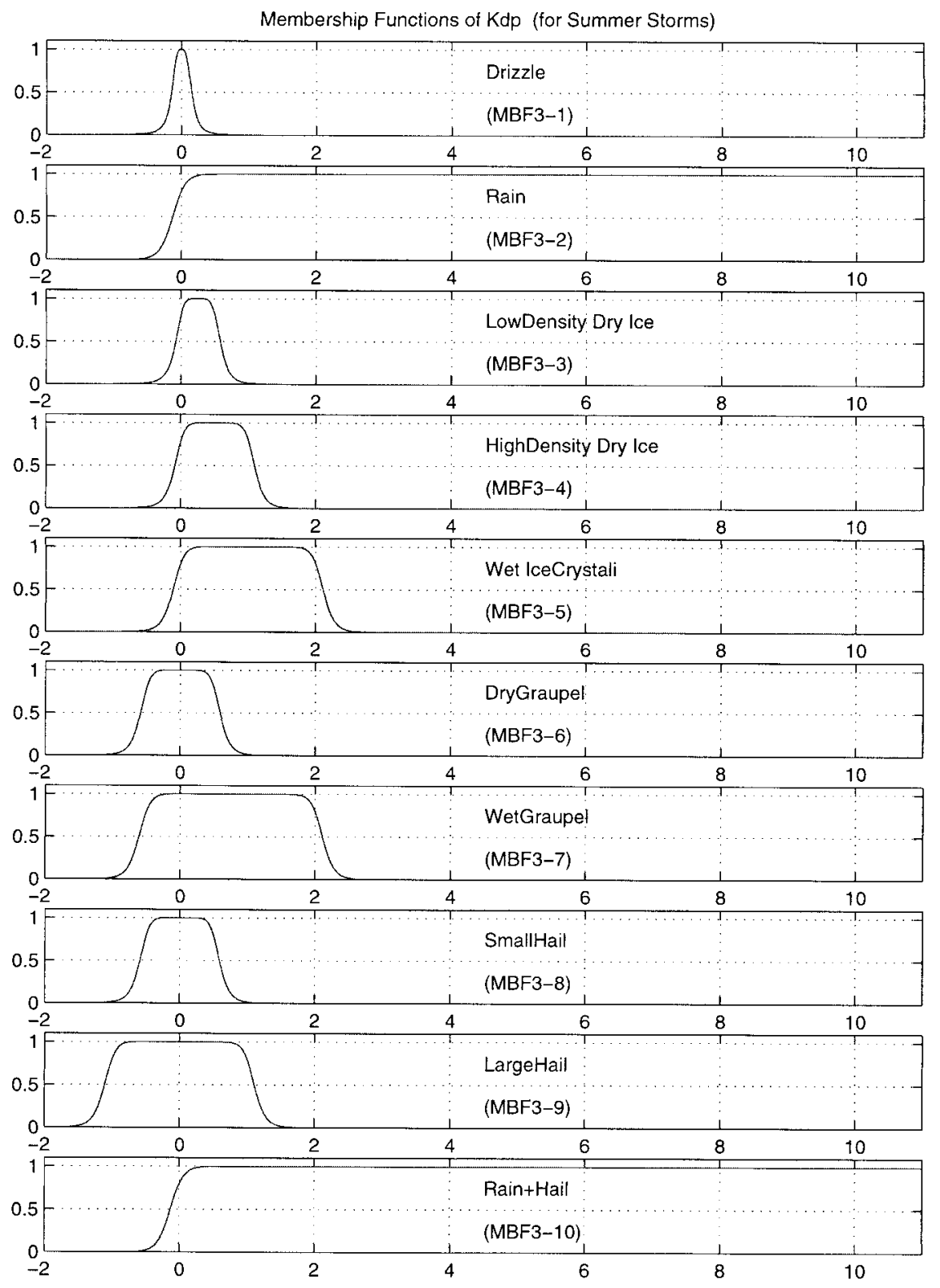

FIG. B1. Fuzzy sets for differential phase shift $K_{\text {DP }}$. 


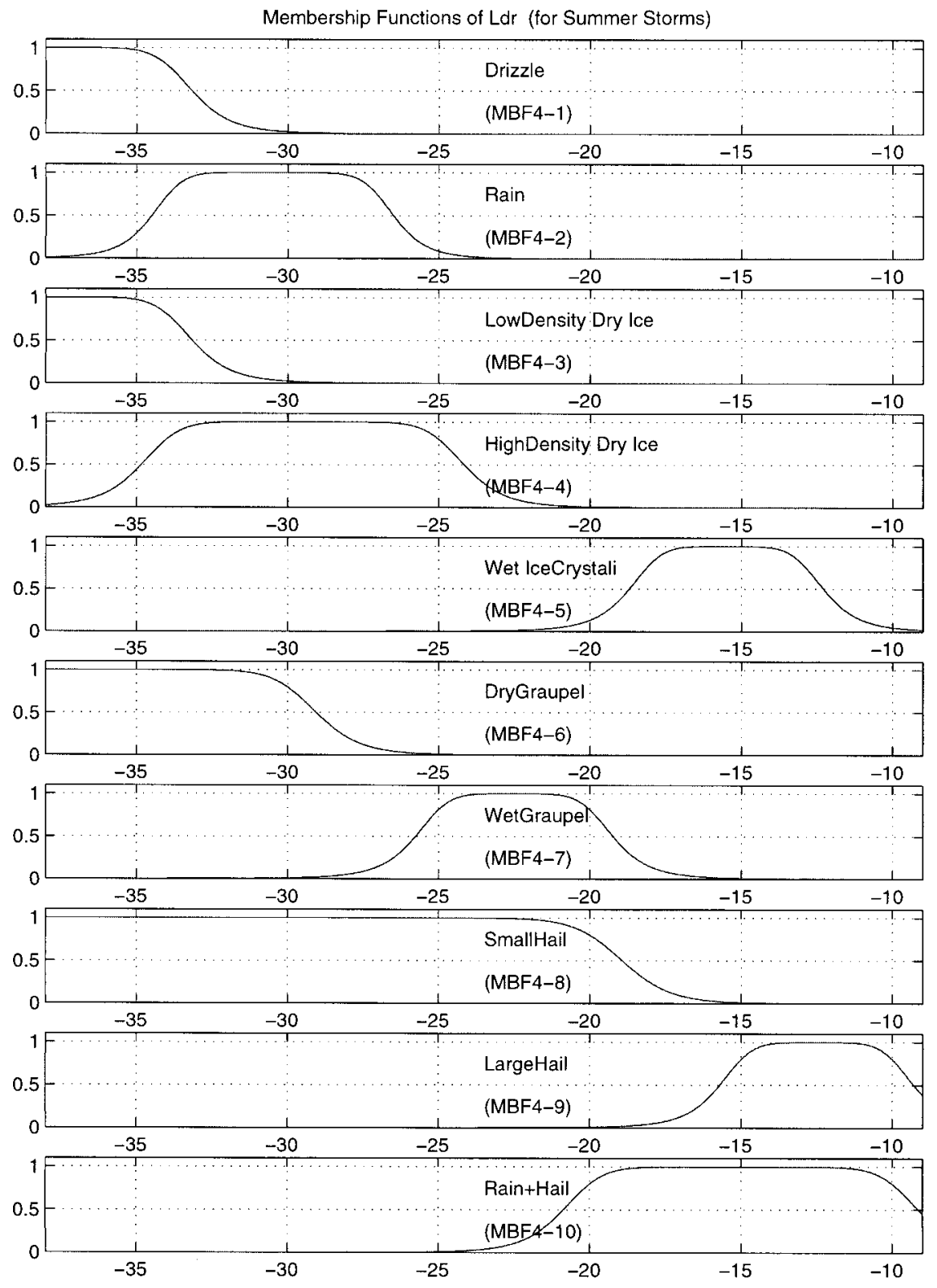

FIG. B2. Fuzzy sets for linear depolarization ratio LDR. 


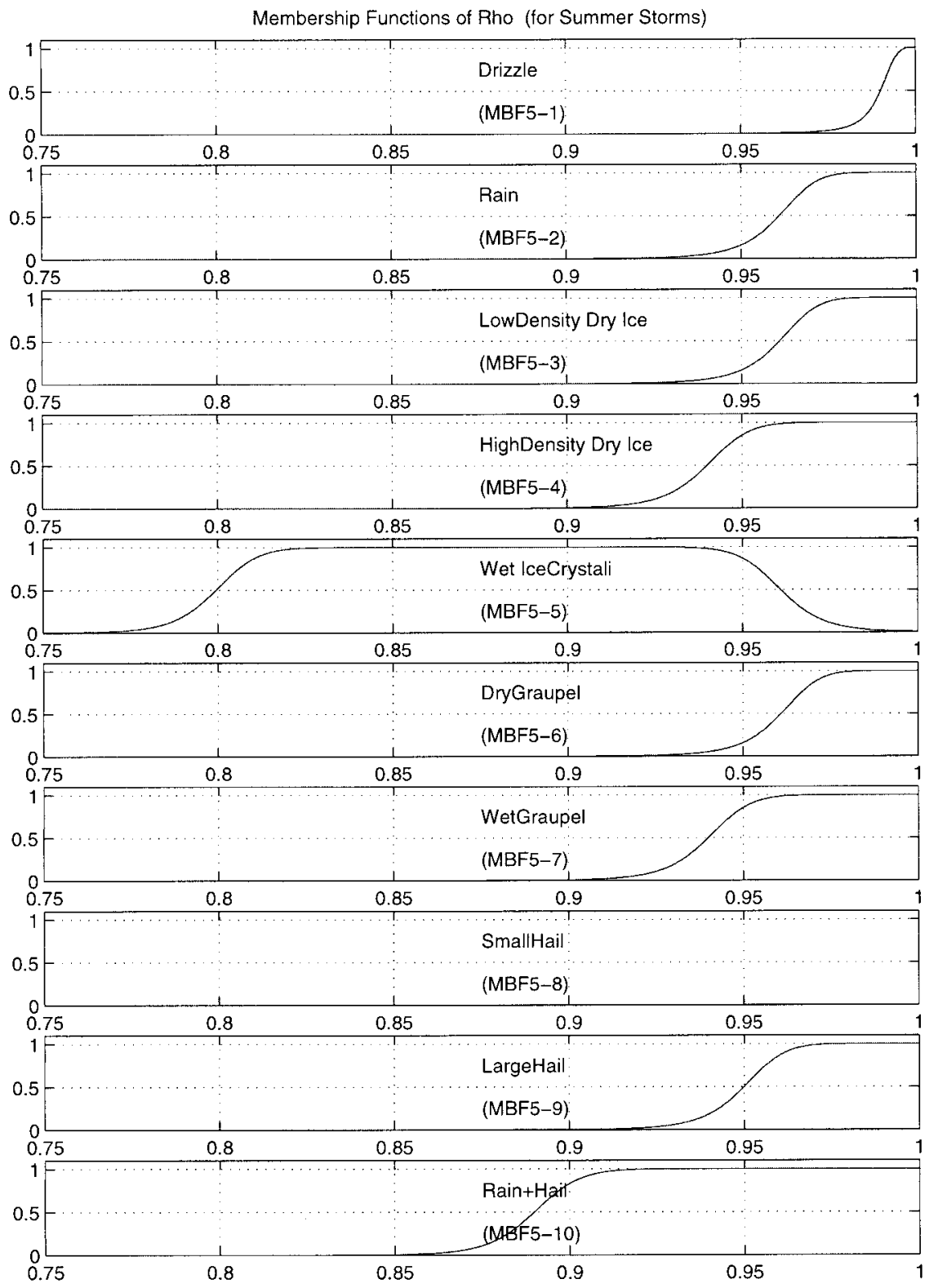

FIG. B3. Fuzzy sets for correlation coefficient $\rho_{h v}$. 
Membership Functions of Zh (for Winter Storms)

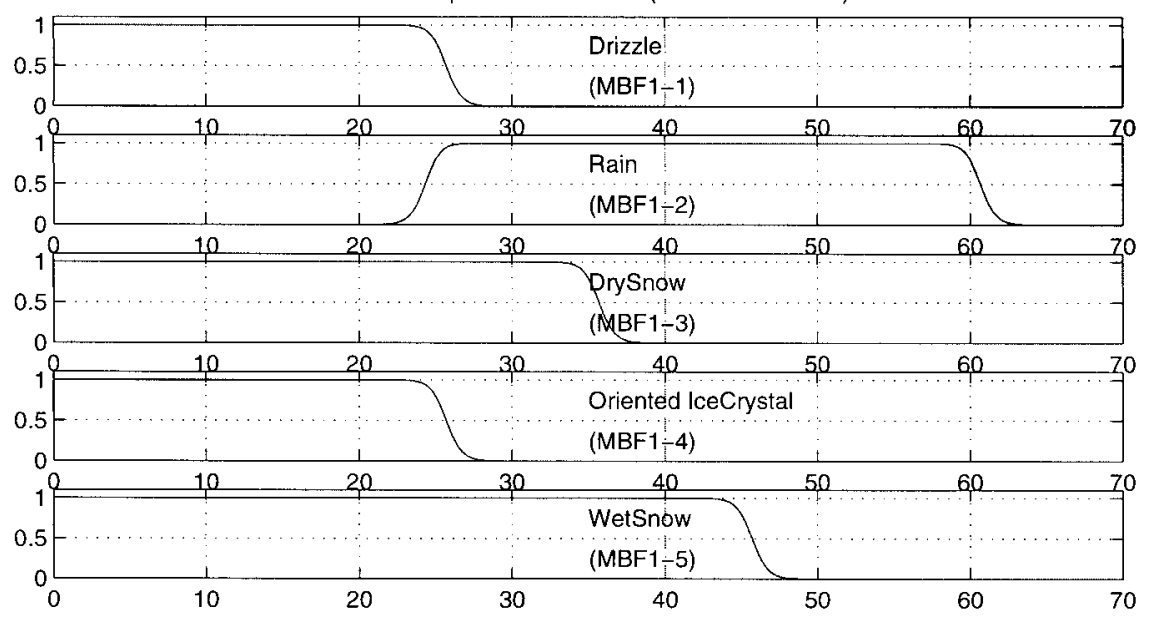

FIG. B4. Membership functions for fuzzy variable $Z_{H}$, and illustration of the fuzzification of $Z_{H}$ to its six fuzzy sets for winter storms.

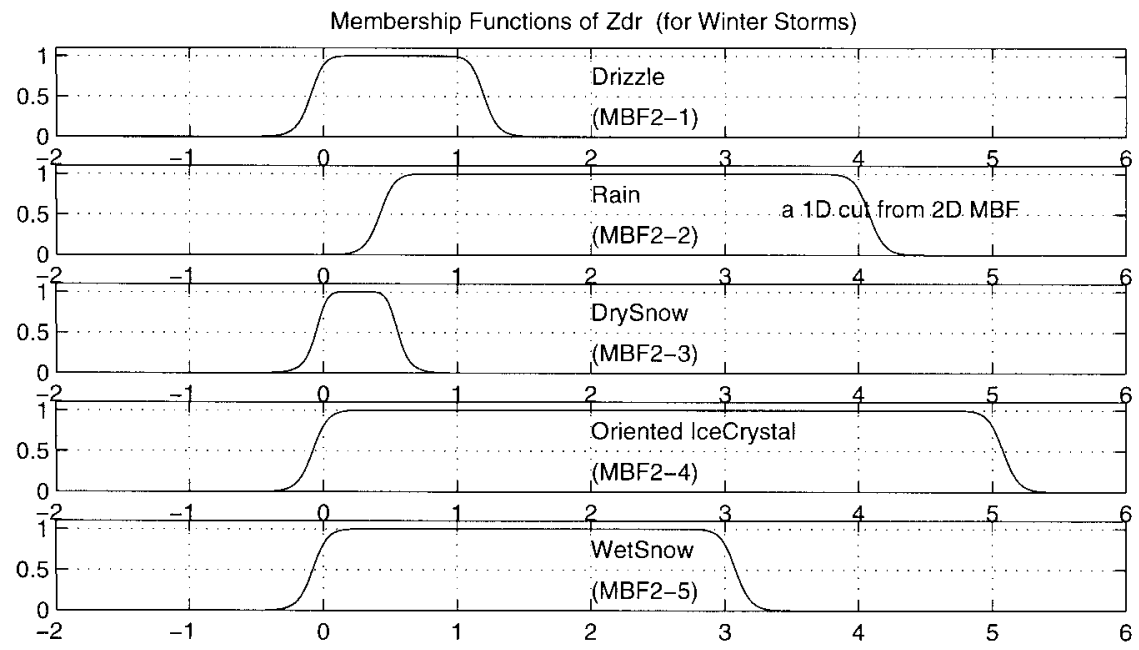

FIG. B5. Fuzzy sets for differential reflectivity $Z_{\mathrm{DR}}$ for winter storms.

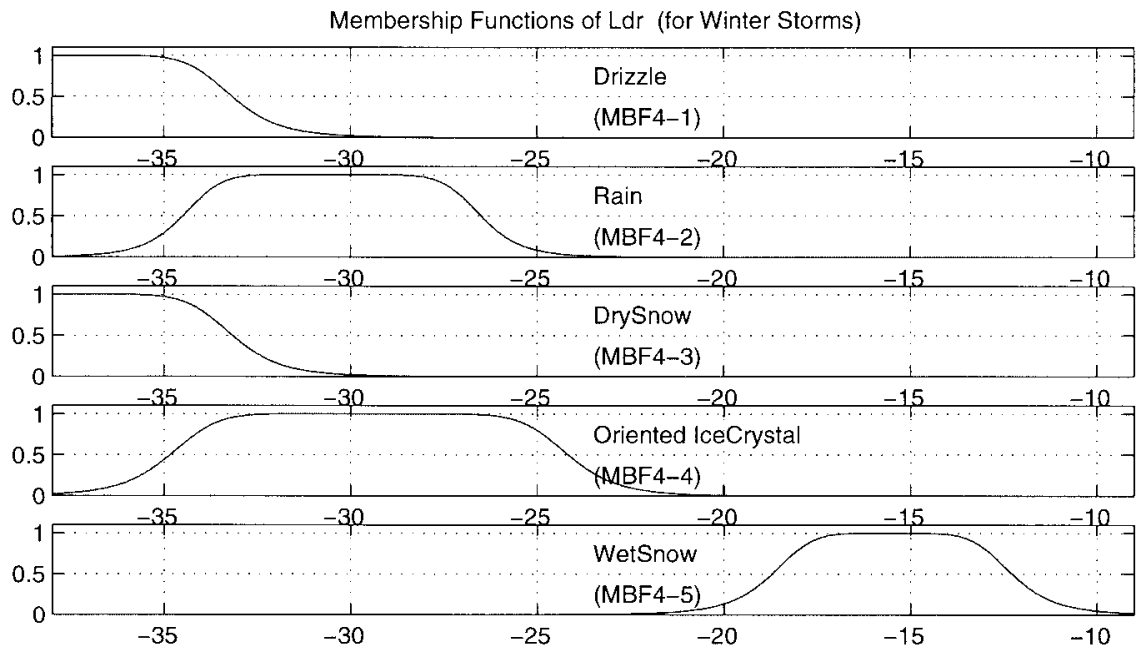

FIG. B6. Fuzzy sets for linear depolarization ratio LDR for winter storms. 


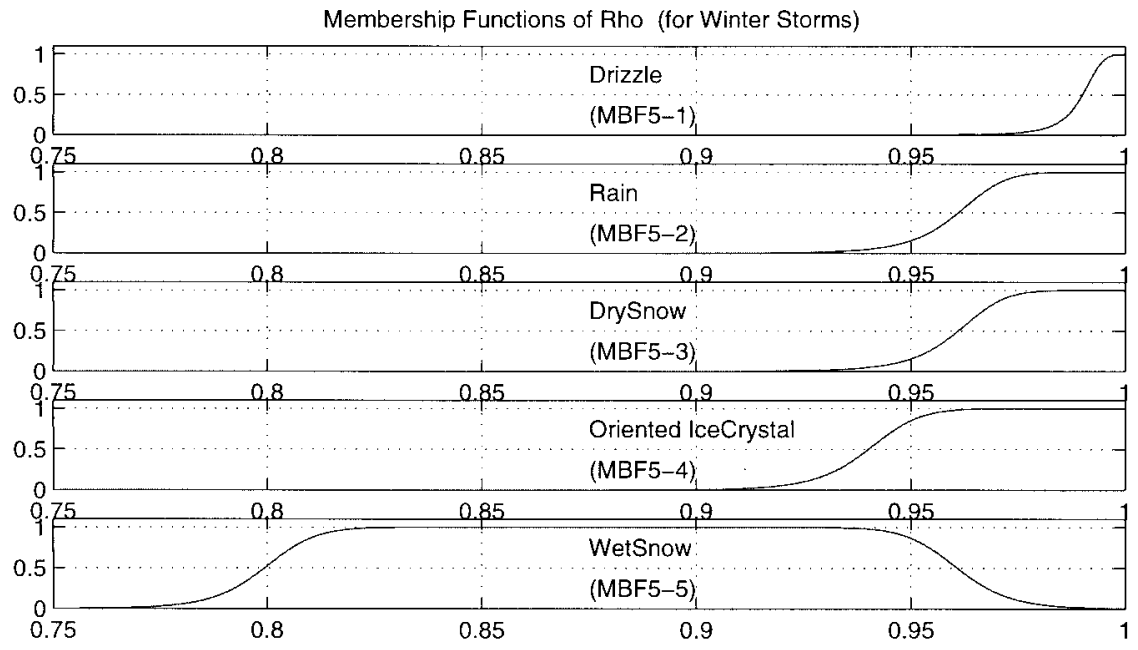

FIG. B7. Fuzzy sets for correlation coefficient $\rho_{h v}$ for winter storms.

\section{REFERENCES}

Aydin, K., Y. Zhao, and T. A. Seliga, 1990: A differential reflectivity radar hail measurement technique: Observations during the Denver hailstorm of 13 June 1984. J. Atmos. Oceanic Technol., 7, $104-113$.

Bringi, V. N., T. A. Seliga, and K. Aydin, 1984: Hail detection with a differential reflectivity radar. Science, 225 (4667), 11451147.

_ _ J. Vivekanandan, and J. D. Tuttle, 1986: Multiparameter radar measurements in Colorado convective storms. Part II: Hail detection studies. J. Atmos. Sci., 43, 2564-2577.

— , V. Chandrasekar, P. Meischner, J. Hubbert, and Y. Golestani, 1991: Polarimetric radar signature of precipitation at S- and C-bands. IEE Proc. F, 138, 109-119.

Hall, M. P. M., J. W. F. Goddard, and S. M. Cherry, 1984: Identification of hydrometeors and other targets by dual-polarization radar. Radio Sci., 19, 132-140.
Heske, T., and J. Heske, 1996: Fuzzy Logic for Real World Design. 1st ed. Annabooks, $428 \mathrm{pp}$.

Höller, H., 1995: Radar-derived mass-concentrations of hydrometeors for cloud model retrievals. Preprints, 27th Conf. on Radar Meteorology, Vail, CO, Amer. Meteor. Soc., 453-454.

Hubbert, J., V. N. Bringi, and L. D. Carey, 1998: CSU-CHILL polarimetric radar measurements from a severe hailstorm in eastern Colorado. J. Appl. Meteor., 37, 749-775.

Straka, J. M., and D. S. Zrnić, 1993: An algorithm to deduce hydrometeor types and contents from multi-parameter radar data. Preprints, 26th Conf. on Radar Meteorology, Norman, OK, Amer. Meteor. Soc., 513-515.

Tong, H., V. Chandrasekar, K. R. Knupp, and J. Stalker, 1998: Multiparameter radar observations of time evolution of convective storms: Evaluation of water budgets and latent heating rates $J$. Atmos. Oceanic Technol., 15, 1097-1109.

Zadeh, L. A., 1983: A computational approach to fuzzy quantifiers in natural languages. Comput. Math., 9, 149-184. 